\title{
Metabolic Engineering of Isoflavones: An Updated Overview
}

\author{
Soo In Sohn ${ }^{1 *}$, Subramani Pandiann ${ }^{1}$, Young Ju Oh², Hyeon Jung Kang ${ }^{1}$, Woo Suk Cho ${ }^{1}$ \\ and Youn Sung $\mathrm{Cho}^{1}$
}

${ }^{1}$ Biosafety Division, Department of Agricultural Biotechnology, National Institute of Agricultural Sciences, Jeonju, South Korea, ${ }^{2}$ Institute for Future Environmental Ecology Co., Ltd., Jeonju, South Korea

Isoflavones are ecophysiologically active secondary metabolites derived from the phenylpropanoid pathway. They were mostly found in leguminous plants, especially in the pea family. Isoflavones play a key role in plant-environment interactions and act as phytoalexins also having an array of health benefits to the humans. According to epidemiological studies, a high intake of isoflavones-rich diets linked to a lower risk of hormone-related cancers, osteoporosis, menopausal symptoms, and cardiovascular diseases. These characteristics lead to the significant advancement in the studies on genetic and metabolic engineering of isoflavones in plants. As a result, a number of

OPEN ACCESS

Edited by: Cristina Garcia-Viguera, Consejo Superior de Investigaciones Cientificas (CSIC), Spain

Reviewed by: Xuebin Zhang, Henan University, China Nik Kovinich York University, Canada

*Correspondence: Soo-In Sohn sisohn@korea.kr

Specialty section: This article was submitted to Plant Metabolism and Chemodiversity,

a section of the journal Frontiers in Plant Science

Received: 20 February 2021 Accepted: 21 April 2021

Published: 07 June 2021

Citation:

Sohn SI, Pandian S, Oh YJ Kang HJ, Cho WS and Cho YS (2021) Metabolic Engineering of Isoflavones:

An Updated Overview.

Front. Plant Sci. 12:670103. doi: 10.3389/fpls.2021.670103 structural and regulatory genes involved in isoflavone biosynthesis in plants have been identified and characterized. Subsequently, they were engineered in various crop plants for the increased production of isoflavones. Furthermore, with the advent of highthroughput technologies, the regulation of isoflavone biosynthesis gains attention to increase or decrease the level of isoflavones in the crop plants. In the review, we begin with the role of isoflavones in plants, environment, and its benefits in human health. Besides, the main theme is to discuss the updated research progress in metabolic engineering of isoflavones in other plants species and regulation of production of isoflavones in soybeans.

Keywords: genistein, isoflavones, metabolic engineering, MYB transcription factors, phenylpropanoid pathway, soybean

\section{INTRODUCTION}

Isoflavones are a class of flavonoids mostly available in leguminous plants where they play pivotal roles in plant-microbe interactions such as rhizobia-legume symbiosis and defense responses (Sugiyama, 2019). Isoflavones are involved in nodulation process in the leguminous plants by inducing the nodulation genes (Subramanian et al., 2006). They also act as a phytoalexins in plants, i.e., compounds produced by the plants during stress or pathogen attacks (Rípodas et al., 2013). Soybeans produce the maximum amount of isoflavones of all the leguminous crops, and they are the only significant dietary source of these groups of compounds (Kraszewska et al., 2007). Isoflavones have a similar size and chemical structure to the human estrogens that binds to both estrogen $\alpha$ and $\beta$ receptors. Therefore, they are commonly referred to as "phytoestrogens" (Messina and Wood, 2008). Isoflavones are present in soybean as glycosylated form; however, their biological activity is from their aglycones. When soy foods are consumed, the soy isoflavones are converted to their aglycones by $\beta$-glucosidase from enteric bacteria (Tsuchihashi et al., 2008). 
In recent years, scientists have been increasingly interested in isoflavones because of their potential health benefits. This can also be seen in the increased number of isoflavone containing nutritional health products in the market. Isoflavones have also been linked to cancer prevention, reduced alcohol intake, prevention of osteoporosis, and cardiovascular diseases (Dixon and Steele, 1999; Pandey et al., 2014). However, this does not mean that consuming isoflavone-rich foods is the ultimate solution to preventing diseases. In certain cases, isoflavones may be needed to consume in impossible quantities to achieve desired health benefits, although there may be some negative effects on human health. Therefore, it is imperative to increase the level of isoflavones in natural environment through metabolic engineering. Hence, understanding the molecular mechanism of isoflavone biosynthesis in various crops is important. This could pave the way to improved production of isoflavone and subsequently helps in the functional food production.

\section{STRUCTURE AND NATURAL ROLE OF ISOFLAVONES IN PLANTS AND ENVIRONMENT}

The general structure of isoflavone (Figure 1) is made up of a 3-phenylchromen-4-one backbone, with the rings denoted by the letters A, C, and B, beginning from the left (Figure 1). The position of phenyl ring in the structure of an isoflavone varies from that of a flavone, which is in position 2 in flavone but in position 3 in isoflavones (Figure 1). Although these compounds have structural similarities, they differ in their chemical behavior, and hence, the synthetic approaches for flavones cannot be used with isoflavones. Isoflavones belong to the large isoflavonoid family, which includes the following groups: isoflavones, isoflavans, isoflavanone, isoflavonols, isoflav-3-enes, $\alpha$-methyldeoxybenzoins, rotenoids, pterocarpans, coumestans, 2-arylbenzofurans, 3-arylcoumarins, and coumaronochromones (Reynaud et al., 2005).

Isoflavones are known to have many effects on plantmicrobe interactions, including control of nodulation, having an antifungal activity, and being precursors to phytoalexin (Yu et al., 2000). Phytoalexins act against both prokaryotic and eukaryotic microorganisms with their large spectrum of defense mechanisms (Paxton, 1981). In soybean, both the simple and complex derivatives of isoflavones act as phytoalexins. The main isoflavone phytoestrogens are genistein, daidzein, and glycitein (Kř́řzová et al., 2019) (Figure 1). A rapid increase in the isoflavonoid levels in soybeans has been reported upon treatment with various pathogens (Graham, 1991, 1995; Lozovaya et al., 2004; Jeandet et al., 2013). Isoflavones also play a role in plant-environment interactions by mediating the symbiosis between plants and $\mathrm{N}_{2}$ fixing bacteria. As plants could not use atmospheric $\mathrm{N}_{2}$, the legumes develop symbiosis with the bacteria and used for its metabolism (Mulligan and Long, 1985). In respect to plant-microbe interaction, the rhizobia attracted by the root exudates move toward the legume roots through positive chemotaxis (Gaworzewska and Carlile, 1982; CaetanoAnolles et al., 1992; Compton et al., 2020). The Rhizobium genes are classified into two classes. Genes that determine the synthesis of exopolysaccharides (exo genes), lipopolysaccharides (lps genes), capsular polysaccharides of $\mathrm{K}$ antigens, and $\beta-1,2-$ glucans ( $n d v$ genes) belong to the one class of genes involved in the synthesis of bacterial cell surface (Iyer and Rajkumar, 2017). The second class of genes comprises nodulation (nod) genes. Isoflavonoids from the plants act as key factor to induce the activation of rhizobial nodulation genes (Philips and Tsai, 1992; Liu and Murray, 2016; Ahmad et al., 2020) and require the participation of the transcriptional-activator protein NodD (Figure 2). In the first step, flavonoids excreted by the plant form a complex with the NodD protein, promoting the transcription of bacterial nod genes (Fisher and Long, 1992; Oldroyd et al., 2011; Del Cerro et al., 2019). In the second step, the bacterium produces lipooligosaccharide signals (Nod factors) (Spaink, 1992; Del Cerro et al., 2019) that cause various root responses through structural nod genes (Spaink et al., 1991). The role of isoflavonoids in root nodule formation is extensively studied in soybean by overexpression and RNAi-mediated gene silencing of IFS (isoflavone synthase) genes (Subramanian et al., 2005). This is not only specific to $\mathrm{N}_{2}$ fixing bacteria, but it also plays an important role in symbiosis with mutualistic fungi (Figure 2). Isoflavones may promote spore germination, hyphal formation and growth, root colonization, and arbuscule formation within the root during the establishment of fungal symbiosis (AbdelLateif et al., 2012). The specific characteristics of utilization of atmospheric $\mathrm{N}_{2}$ for their metabolism signify the legumes as important plant species for the development of soil quality and as an alternative for chemical $\mathrm{N}_{2}$ fertilizers.

\section{ROLE OF ISOFLAVONES IN HUMAN HEALTH}

In the last few decades, the consumption of isoflavone-rich functional foods is highly recommended owing to the potential health protection against some aging-associated diseases such as cardiovascular disease, osteoporosis, hormone-related cancer, and cognitive impairment (Gilbert and Liu, 2013; Vitale et al., 2013; Chi et al., 2016) (Figure 3). Even though isoflavones present in a variety of plant-derived products such as cereals, potatoes, vegetables, and fruits, the richest sources in the human diet are soy-derived foods (Kraszewska et al., 2007). For instance, the US Food and Drug Administration announced in 1999 that consuming soy protein ( $25 \mathrm{~g} /$ day) (i.e., soy isoflavone) on a daily basis may decrease the risk of coronary heart disease by reducing the blood cholesterol content. Various clinical studies have revealed that isoflavone favorably lowers the risk of cardiovascular disease because of its estrogenic property (Yan et al., 2017; Nachvak et al., 2019). A systemic review that evaluated the impact of isoflavone diet on cardiovascular disease in 1,307 menopausal $(n=139)$ and postmenopausal ( $n=1,268)$ women concluded that supplementation of soy isoflavone through diet reduces the cardiovascular risk by lowering the cholesterol and triglyceride plasma concentrations and also oxidative stress (Perna et al., 2016). The clinical study by Tikkanen and Adlercreutz (2000) suggested that 
<smiles>O=c1c(-c2ccccc2)coc2ccccc12</smiles><smiles>O=c1c(-c2ccc(O)cc2)coc2cc(O)ccc12</smiles>

Daidzein<smiles>O=c1c(-c2ccc(O)cc2)coc2cc(O)cc(O)c12</smiles>

Genistein<smiles>COc1cc2c(=O)c(-c3ccc(O)cc3)coc2cc1O</smiles>

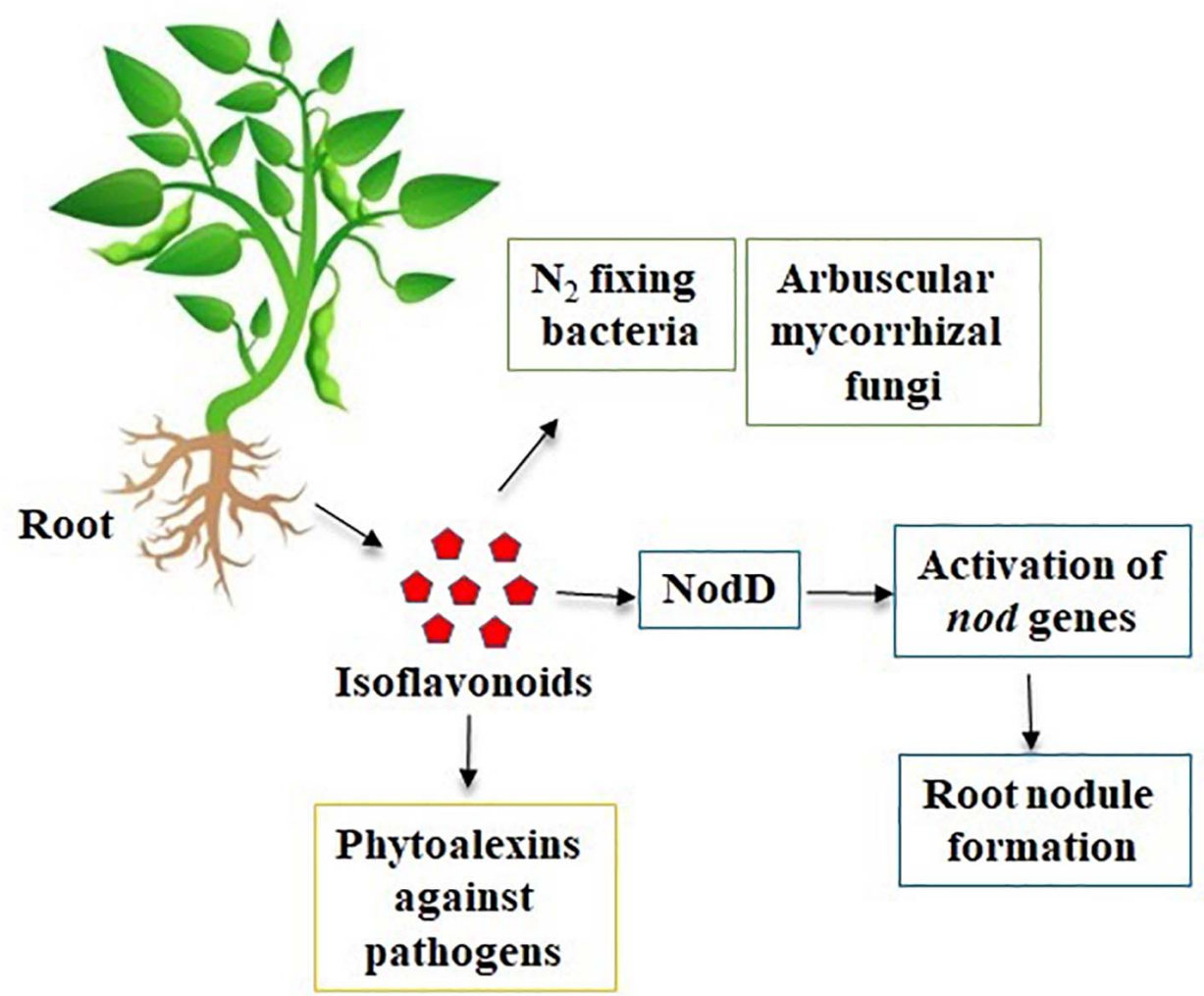

FIGURE 2 | Natural role of isoflavones in plants and environmental interactions.

dietary supplementation of isoflavone reduces low-density lipoprotein cholesterol concentrations and increased highdensity lipoprotein concentration. However, the recent studies demonstrated that other constituents of soy, including proteins, fiber, and phospholipids, may play an important role in balancing the cholesterol profile than isoflavones. Some evidence hints that equol, a substance converted from soy isoflavones by the action of the intestinal microflora, seems to be playing a huge role in the reduction of cholesterol content (Nestel et al., 2004; Wu et al., 2007). 


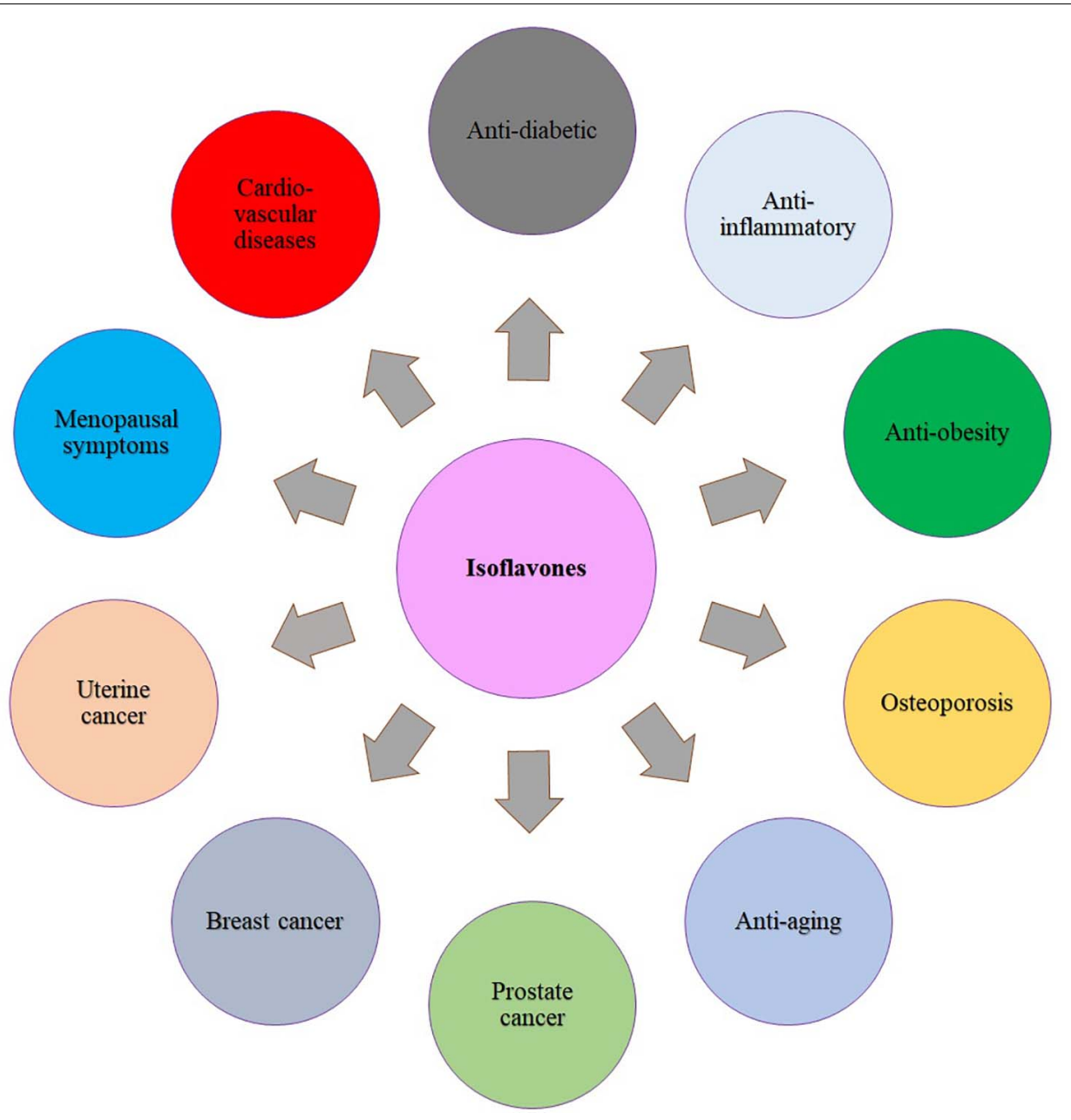

FIGURE 3 | Benefits of isoflavones in human health.

As the ovarian growth hormone (estrogen) has been linked to breast and uterine cancers, isoflavones with estrogenic effects may be used as an effective treatment to thwart breast and uterine cancer (Kumar et al., 2002). However, because of the estrogen-like properties of soy isoflavones, it may stimulate the development of estrogen-sensitive breast tumors in a few cases (Messina and Loprinzi, 2001); hence, understanding the action behind the intake of soy isoflavones and breast cancer reduction is still controversial. In contrast to these conclusions, epidemiologic results suggest that higher soy intake is linked to an approximately one-third lower incidence of breast cancer in Asian women (Wu et al., 2008). Other studies found that Japanese breast cancer patients have better survival rates than Western women, even after the diagnosis (Wu et al., 1996, 2002; Yamamoto et al., 2003). The anti-prostate cancer efficacy of isoflavones was elaborately reviewed by the Mahmoud et al. (2014). Both epidemiological and clinical studies revealed that dietary supplements containing isoflavones could be an effective alternative treatment for various hormonal disorders (Chen et al., 2019; Daily et al., 2019). One of such age-related hormonal diseases is osteoporosis, a bone loss disease that mostly occurs in women who are at menopause time. At the stage of menopause, the low secretion of ovarian hormone, i.e., estrogen, causes an imbalance between resorption and formation of new bone, and subsequent bone loss occurs (Hooper et al., 2010; Taku et al., 2011). The genistein is a well-known isoflavone phytoestrogen that plays an important role in prevention of osteoporosis by acting as an estrogen receptor modulator (Figure 3). Data from epidemiological studies revealed that the risk of osteoporosis has reduced in women who consume foods with high isoflavone content (Abdi et al., 2016).

A meta-analysis showed that supplementation of isoflavones greatly increases bone mineral density and decreases the marker of bone resorption, i.e., urinary deoxypyridinoline (Wei et al., 2012; Atcharaporn et al., 2014). They also found that there are numerous factors that could significantly influence the function of isoflavone on bone resorption and formation, such as menopausal status, dose of isoflavone, and intervention duration. Moreover, the menopausal period is associated with cardiovascular diseases due to low production of estrogen. As genistein has antiaging efficacy in various estrogen-dependent aging conditions, it can be used for cosmetic preparations 
to improve skin tone and reduce wrinkles and skin dryness (Wang et al., 2010; Geeta et al., 2019). The estrogenic effects of isoflavones, such as genistein and daidzein, were also used to improve the quality of sleep in Japanese adults (Cui et al., 2015). Furthermore, a previous study indicated that administration of soy isoflavones (daidzein, genistein, and glycetin) $(20 \mathrm{mg} /$ day $)$ synergistically improved irritable bowel disease by combination with vitamin D in female patients (Jalili et al., 2016). Owing to its importance in natural processes and in human health, a plethora of researchers started to concentrate on the improved productions of isoflavones through metabolic engineering.

\section{ISOFLAVONE BIOSYNTHESIS AND THE ROLE OF BIOSYNTHETIC GENES}

Isoflavonoids are limited primarily to the Leguminosae and a few other species. Isoflavones are synthesized via the phenylpropanoid pathway from which plants produce most of the secondary metabolites including lignin, flavone, flavonol, anthocyanin, and tannin, etc. Isoflavones are produced by using intermediate substrates of phenylpropanoid pathway, naringenin, and liquiritigenin, respectively. Naringenin is common in most plants, and other compounds of phenylpropanoid pathway, such as flavones, flavonol, and anthocyanin, are also derived from it (Figure 4). Another intermediate substrate of phenylpropanoid pathway, liquiritigenin, is produced by chalcone isomerase (CHI) and chalcone reductase (CHR). CHI is present in most plants, whereas $\mathrm{CHR}$ is specific for legumes. Isoflavone reaction comprised two steps. Cytochrome P450-mediated hydroxylation associated with 2,3-aryl migration of the $\mathrm{B}$ ring in $2 \mathrm{~S}$ flavanones forms a 2-hydroxyisoflavanone using IFS (Figure 4). Then, this is dehydrated into the isoflavones (genistein and daidzein) through the natural reaction catalyzed by specific dehydratase enzyme (Kochs and Grisebach, 1986; Hakamatsuka et al., 1990, 1998).

Generally, genes on the phenylpropanoid pathway are known to be triggered by environmental stresses (nutrient deficiency, excessive heat, and pathogen attack, etc.) through developmental and tissue-specific regulation (Dixon and Paiva, 1995). Many of the upstream phenylpropanoid pathway enzymes, namely, phenylalanine ammonia lyase (PAL), cinnamate 4-hydroxylase (C4H), p-coumaroyl-CoA (4CL), CHS, and CHI, have been well characterized. PAL catalyzes the deamination of phenylalanine to produce trans-cinnamic acid, which is then transformed to $p$-coumaric acid through an oxidation reaction catalyzed by $\mathrm{C} 4 \mathrm{H}$. After 4CL activates the thio esterification, $p$-coumaroyl-CoA directed into the branched pathway resulted in the production of lignins and flavonoids. $\mathrm{C} 4 \mathrm{H}$ belongs to the CYP73 family of the large group of cytochrome P450 monooxygenases (Teutsch et al., 1993). Cytochrome P450 monooxygenases are playing a role in the biosynthesis of a wide range of metabolites in plants (e.g., fatty acids, phenylpropanoids, alkaloids, and terpenoids) and detoxification of herbicides and pesticides (Chapple, 1998). The accumulation of chalcone in plant tissue is rare. $\mathrm{CHI}$ catalyzes the stereospecific isomerization of chalcones into corresponding (2S)-flavanones, naringenin, and liquiritigenin
(Figure 4). Even in the absence of CHI, chalcones can be spontaneously isomerized to form (2S)-flavanones, at a slower rate (Jez et al., 2000). CHR, which is not present in nonlegume species, belongs to the aldo-keto-reductase superfamily and is involved in the synthesis of $6^{\prime}$-deoxychalcone, which is the precursor for daidzein. Among the genes, flavanone-3hydroxylase $(\mathrm{F} 3 \mathrm{H})$ uses naringenin as a substrate; therefore, it competes with IFS for the formation of isoflavones. The phenylpropanoid pathway genes and their roles are elaborated below.

\section{Phenylalanine Ammonia-Lyase Genes}

Phenylalanine ammonia-lyase is a key enzyme in the phenylpropanoid pathway that catalyzes the first step of the pathway (Kervinen et al., 1997; Wang et al., 2007) found in plants (Ritter and Schulz, 2004; Francini et al., 2008), fungi (Hyun et al., 2011), and bacteria (Xiang and Moore, 2005). There is a positive correlation relationship between PAL activity and anthocyanin content in various fruits such as grapes (Hrazdina et al., 1984), strawberries (Given et al., 1988), and apples (Steyn et al., 2004), whereas negative correlation was detected in litchi fruit (Wang et al., 2004). PAL genes have been transformed and characterized in different plant species, including tobacco (Nagai et al., 1994), ginkgo (Cheng et al., 2005), Mongolian milkvetch (Liu et al., 2006), banana (Wang et al., 2007), Salvia (Hu et al., 2009), coffee (Lepelley et al., 2012), and so on.

Synthesis of phenylpropanoids is regulated by multiple steps, including the entry of sugars into the shikimic acid pathway, Phe into the general phenylpropanoid pathway, and the activated coenzyme A (CoA) esters into various subbranches of the phenylpropanoid pathway. PAL catalyzes the nonoxidative deamination of $\mathrm{L}$-Phe to produce cinnamic acid, a reaction that is thought to be a central control point for which there is carbon flux into this pathway. PAL tends to be a gene family that exists universally in higher plants, and observation of $P A L$ isoforms is common. The importance of this diversity is uncertain, but evidence of metabolic channeling within phenylpropanoid metabolism indicates that partitioning of photosynthesis into specific branches of phenylpropanoid metabolism could be involved by labile multienzyme complexes containing specific isoforms of PAL (Hrazdina and Wagner, 1985; Rasmussen and Dixon, 1999). PAL is localized in crucial metabolic position, linking the primary and secondary metabolism. PAL as a rate-limiting enzyme is thought to regulate overall flux into phenylpropanoid metabolism (Bate et al., 1994). In vitro PAL activity shows that feedback inhibitory regulation of its own product, trans-cinnamate and trans-cinnamic acid, was proposed to alter the transcription of $P A L$ genes in vivo (Jorrin and Dixon, 1990; Mavandad et al., 1990; Appert et al., 1994).

\section{Chalcone Synthase Genes}

The first flavonoid biosynthetic gene CHS was isolated from parsley (Kreuzaler et al., 1983; Schulze-Lefert et al., 1989). CHS forms a tetraketide intermediate that is cyclized into $4,2^{\prime}, 4^{\prime}, 6^{\prime}$ tetrahydroxychalcone (chalcone) using $p$-coumaroyl-CoA three malonyl-CoA extender molecules. CHS belongs to the multigene family, for example, 12 in petunia (Koes et al., 1989) and 


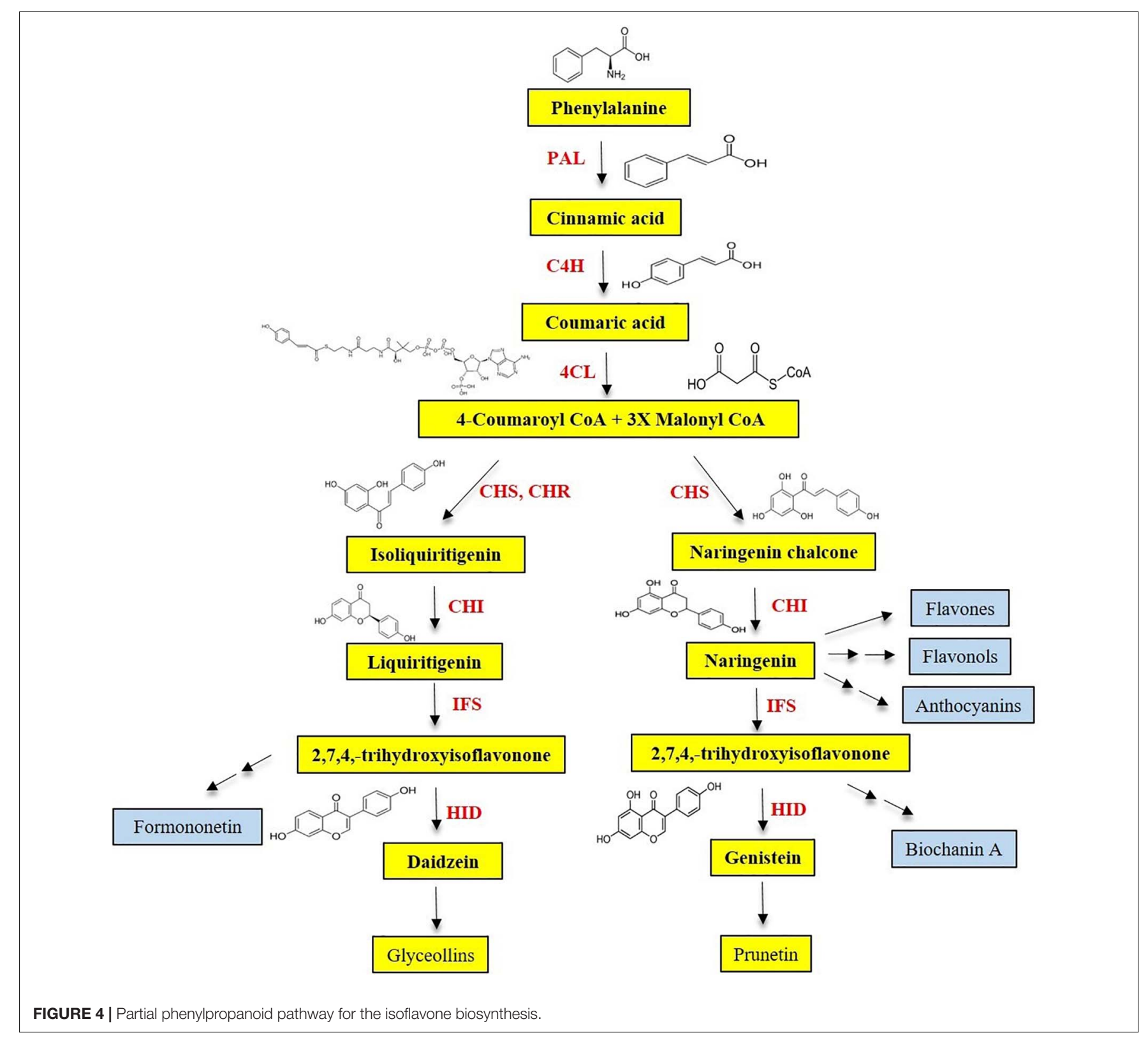

8 in soybean (Matsumura et al., 2005). Few of the species has single-copy genes also such as Arabidopsis (Feinbaum and Ausubel, 1988) and Petroselinum crispum (Weisshaar et al., 1991). Alfalfa CHS2 with three-dimensional structure reveals the active site that catalyzes chalcone formation. The catalytic center of CHS is formed by four residues (Cys164, His303, Asn336, and Phe215), which are exclusively conserved in other CHS-like enzymes, such as 2-pyrone synthase, bibenzyl synthase, stilbene synthase, acridone synthase, and the rppA CHS-like protein. Structural and functional studies revealed that Cys164 acts as the nucleophilic thiolate in the loading reaction and as the covalent thioester-anchor for the acyl-enzyme chain during the elongation reactions. Furthermore, in the elongation reaction, His303 and Asn336 catalyze the decarboxylation of malonyl-CoA and stabilize the intermediate state in the condensation phases of polyketide formation. Substrates and reaction intermediates at the active site are oriented by Phe215. CHS supplies the important substrate chalcone for the isoflavone biosynthesis, and its expression level plays an important role in isoflavonoid accumulation in plants (Tuteja et al., 2004). Downregulation of CHS genes plants may lead to the complete absence of flavones and isoflavone biosynthesis. However, these may lead to the several functions of the plants such as male sterility (Napoli et al., 1999).

\section{Chalcone Reductase Genes}

Other than CHS, leguminous plants also have CHR, which catalyze the intermediate of the multistep CHS reaction, producing chalcone and 4,2',4;-trihydroxychalcone (deoxychalcone) as a result of their combined catalytic activity. 
In response to herbivore or pathogen attacks, CHR sits at a key branch of the biosynthetic pathway and synthesizes a set of deoxychalcone-derived phytoalexins such as isoflavonoids, coumestans, pterocarpans, and isoflavans. CHR occurrence was first discovered in Glycyrrhiza echinata crude extracts (licorice) (Ayabe et al., 1988). Subsequently, CHR was purified, and the CHR cDNA (GmCHR1) from Glycine max (soybean) was cloned (Welle and Grisebach, 1988). Other homologs of GmCHR ( $\mathrm{G} m \mathrm{CHR} 2, \mathrm{GmCHR} 3, \mathrm{GmCHR} 4$, and GmCHR2A) have been identified and tested for their significance (Subramanian et al., 2006; Sepiol et al., 2017). Graham et al. (2007) have identified four $\mathrm{GmCHR}$ genes through mining of soybean ESTs. Until now, CHR-like enzymes have been discovered in a wide range of leguminous and some nonleguminous plant species, such as Medicago sativa (alfalfa) (Ballance and Dixon, 1995), Glycyrrhiza glabra (licorice), and Fragaria ananassa (strawberry) (Manning, 1998), Pueraria lobata (Kudzu vine), G. echinata (licorice) (Akashi et al., 1999), Lotus japonicas (Shimada et al., 2006), Pueraria montana (He et al., 2011), and G. glabra (Hayashi et al., 2013). As a result of sequence analysis, CHR was found unrelated to known ketoreductase domains of fatty acid synthases (Price et al., 2001; Cohen-Gonsaud et al., 2002) and $\beta$-polyketide synthases (Staunton and Weissman, 2001). However, aldo-ketoreductase superfamily enzymes from primary metabolism, such as aldose reductase and $3 \alpha$-hydroxy steroid dehydrogenase, were found to have sequence similarities with CHR (Mameda et al., 2018).

\section{Chalcone Isomerase Genes}

Most of the plants do not accumulate the chalcones. During the early stages of flavonoids biosynthesis, CHI catalyzes the intramolecular cyclization of chalcone and $6^{\prime}$-deoxychalcone both generated by the upstream enzyme chalcone synthase, into (2S)-naringenin and (2S)-5-deoxyflavanone, respectively (Holton and Cornish, 1995; Jez and Noel, 2000). CHI ensures the formation of biologically active (2S)-flavanones as chalcones naturally cyclize in solution to yield an enantiomeric mixture of flavanones. For instance, the metabolic precursor of anthocyanin pigments such as (2S)-naringenin and mutations in the $\mathrm{CHI}$ genes have been linked to variations in floral pigmentation (Burdick, 1958). Recently, the introduction of the petunia CHI gene was recently introduced into the tomato plants, resulting in fruits with higher flavanol content (Kang et al., 2014).

In the legume L. japonicas, two types of CHIs coexist with distinctive phylogenic lineages (Shimada et al., 2003). The type I CHIs are commonly present in the plant kingdom, which converts naringenin chalcone to naringenin. On the other hand, the type II CHI tends to be legume-specific and have additional catalytic activity, allowing them to convert 4,2',4-tryhydroxychalcone (isoliquiritigenin) into (2S)-7, $4^{\prime}$ dihydroxyflavanone (liquiritigenin). A type II CHI isolated from alfalfa ( $M$. sativa) has been extensively studied structurally and mechanistically (Jez et al., 2000, 2002; Hur et al., 2004; Sun et al., 2019). According to structure-function analyses, the formation of a hydrogen bond network between the active site of $\mathrm{CHI}$ and its substrates appears to be important for the enzyme's catalytic activity (Jez et al., 2002; Hur et al., 2004). Ralston et al.
(2005) reported that there are four types of CHI based on the phylogenetic relationships, but types III and IV do not have chalcone cyclization activity like types I and II. Until now, CHI genes have been transformed and identified in several plants including Pterolophia hybrida (Van et al., 1988), M. sativa (Jez et al., 2000), L. japonicas (Shimada et al., 2003), Oryza sativa (Druka et al., 2003), G. max (Ralston et al., 2005), Ginkgo biloba (Cheng et al., 2011), Ipomoea batatas (Guo et al., 2015), tomato (Muir et al., 2001; Lim and Li, 2016), and Chamaemelum nobile (Wang et al., 2018), etc.

\section{Isoflavone Synthases Gene}

Isoflavone synthases belong to the cytochrome P450 family, and they are extremely labile in the cells. In the phenylpropanoid pathway, IFS plays an important role that redirects the intermediates of flavonoid pathway to the isoflavonoid pathway. It catalyzes the committed step of isoflavonoid biosynthesis by producing the 2-hydroxyisoflavone from the flavone intermediates such as naringenin and liquiritigenin (Liu et al., 2002). The resulted 2-hydroxyisoflavone is dehydrated by the isoflavone dehydratase (HID) to produce basic isoflavone compounds such as genistein and daidzein. The IFS gene has been cloned and characterized in various plants, including Arabidopsis, tobacco, rice, and tomato, etc. (Table 1). Cloning of IFS encoding genes to various plant species paved way for the genetic engineering for the synthesis of isoflavone compounds in the plants which naturally do not produce isoflavones (Table 1).

Initially, it is thought that IFS is specific to legumes and encoding genes only in leguminous plants, but researchers found that IFS genes in other plants such as Beta vulgaris (Jung et al., 2000), Psoralea corilyfolia (Misra et al., 2010) suggested that IFS can be found in other crops and medicinal plants. There are two isoflavone synthases, IFS1 and IFS2, isolated from soybean which is a having high level of genetic similarity, but they have different efficiency in converting the flavones in to the isoflavones (Jung et al., 2000). Expression analysis revealed that both the IFS1 and IFS2 had different level of expression in different environmental conditions with IFS1 mainly found in root and seed coat, whereas IFS2 can be found in embryos and seed pods (Dhaubhadel et al., 2003; Subramanian et al., 2004). In vitro system using yeast, when the naringenin and liquiritigen were used as substrates, IFS1 had a twofold higher activity compared to IFS2. During the soybean embryo development, the expression of IFS2 gene was significantly increased for 70 days after the pollination (Dhaubhadel et al., 2007).

\section{Isoflavone Dehydratase Genes}

Isoflavone dehydratase belongs to the carboxylesterase gene family, which is involved in the final step of isoflavonoid biosynthesis that produces the genistein and daidzein from the isoflavone skeleton. HID was first identified and purified from the $P$. lobata by rapid enzyme assay method (Hakamatsuka et al., 1998), but the amino acid sequence is not available. Compared to other genes involved in the phenylpropanoid pathway, such as CHS, CHI, and IFS, this gene (HID) is less characterized. The problem in characterizing the HID is the instability of its substrate 2-hydroxyisoflavanones. Later HID genes were 
TABLE 1 | Metabolic engineering of isoflavone biosynthetic genes in various plants.

\begin{tabular}{|c|c|c|c|c|c|}
\hline S. no. & Plants & Genes & Promoter & Purpose & References \\
\hline 1 & Arabidopsis thaliana & GmIFS & CaMV $35 S$ & Accumulation of genistein & Jung et al., 2000 \\
\hline 2 & $\begin{array}{l}\text { Tobacco (Nicotiana tabacum) Maize } \\
\text { BMS cell lines }\end{array}$ & GmIFS & CaMV $35 S$ & Not identified & Yu et al., 2000 \\
\hline 3 & Maize BMS cell lines & $\begin{array}{l}\text { GmIFS and } \\
\text { Maize CRC }\end{array}$ & CaMV $35 S$ & Accumulation of genistein & Yu et al., 2000 \\
\hline 4 & Arabidopsis thaliana & GmIFS, MtCHI & CaMV $35 S$ & Accumulation of genistein & Liu et al., 2002 \\
\hline 5 & Alfalfa (Medicago sativa) & MtIFS1 & CaMV $35 S$ & $\begin{array}{l}\text { Accumulation of genistein, glycosides of biochanin } \\
\text { A, formononetin, and daidzein }\end{array}$ & $\begin{array}{l}\text { Deavours and } \\
\text { Dixon, } 2005\end{array}$ \\
\hline 6 & Rice (Oryza sativa L.) & GmIFS & CaMV $35 S$ & Accumulation of genistein & $\begin{array}{l}\text { Sreevidya et al., } \\
2006\end{array}$ \\
\hline 7 & Rice (O. sativa L.) & maize C1-R-S & prolamin & $\begin{array}{l}\text { Dihydroquercetin, dihydroisorhametin, 3'-O-methyl } \\
\text { quercetin }\end{array}$ & Shin et al., 2006 \\
\hline 8 & Tobacco (N. tabacum) & $\begin{array}{l}\text { IFS/CHI fusion } \\
\text { protein }\end{array}$ & 1. CaMV $35 S$ & $\begin{array}{l}\text { Increased accumulation of genistein and genistein } \\
\text { glycosides }\end{array}$ & $\begin{array}{l}\text { Tian and Dixon, } \\
2006\end{array}$ \\
\hline 9 & Tobacco (N. tabacum) & GmIFS & CaMV 355 & Accumulation of genistein & Liu et al., 2007 \\
\hline 10 & Lettuce (Lactuca sativa) & GmIFS & CaMV $35 S$ & Accumulation of genistein & Liu et al., 2007 \\
\hline 11 & Petunia (Petunia hybrida Vilm.) & GmIFS & CaMV 355 & Accumulation of genistein & Liu et al., 2007 \\
\hline 12 & Tomato (Solanum lycopersicum) & GmIFS2 & CaMV 355 & Accumulation of genistein & Shih et al., 2008 \\
\hline 13 & Tobacco & PCIFS & CaMV $35 S$ & Accumulation of genistein and daidzein & Misra et al., 2010 \\
\hline 14 & Rapeseed (Brassica napus) & GmIFS2 & CaMV $35 S$ & Accumulation of Genistein & Li et al., 2011 \\
\hline 15 & Rice (O. sativa L.) & $\begin{array}{l}\text { PAL, CHS, and } \\
\text { GmIFS1 }\end{array}$ & $\begin{array}{l}\text { Glu-B1 and } \\
\text { oleosin }\end{array}$ & $\begin{array}{l}\text { Accumulation of naringenin, kaempferol, genistein } \\
\text { and apigenin }\end{array}$ & Ogo et al., 2013 \\
\hline 16 & Rice (O. sativa L.) & Maize Lc & Glutelin Gt1 & Not identified & Song et al., 2013 \\
\hline 17 & Tobacco (N. tabacum) & $\begin{array}{l}\text { AtMYB12 and } \\
\text { GmIFS1 }\end{array}$ & CaMV 355 & Enhanced biosynthesis of isoflavones and flavonols & Pandey et al., 2014 \\
\hline 18 & Rice (O. sativa L.) & $\begin{array}{l}\text { SpdIFS1 and } \\
\text { SpdIFS2 }\end{array}$ & $G / b-1$ & Accumulation of genistein & Sohn et al., 2014 \\
\hline 19 & Barrel medic (Medicago truncatula) & $\begin{array}{l}\text { GmIFS1, } \\
\text { GmCHS7, and } \\
\text { GmCHI1A }\end{array}$ & CaMV $35 S$ & $\begin{array}{l}\text { Increased accumulation of genistein, daidzein, } \\
\text { biochanin A, and formononetin }\end{array}$ & Gou et al., 2016 \\
\hline 20 & Onion (Allium cepa L.) & GmIFS & CaMV 355 & Increased accumulation of genistein & Malla et al., 2021 \\
\hline
\end{tabular}

identified and characterized from two plants, including licorice and soybean (Akashi et al., 2005). Site-specific mutagenesis in the GmHID revealed that the oxyanion and catalytic triad are important for the dehydratase and esterase activity of these genes. Shimamura et al. (2007) have overexpressed both IFS and HID genes in lotus, to understand the functional role of the HID in the isoflavone biosynthesis. The GmHID introduced was produced and increased the amount of genistein and daidzein in the lotus as the GmHID has broad specificity to both the $4^{\prime}$-methoxy and $4^{\prime}$-hydroxy substrates. The HID enzyme activity is an important limiting factor in the isoflavone biosynthesis and its level in the legumes (Du et al., 2010).

\section{REGULATION OF ISOFLAVONE PRODUCTION THROUGH GENETIC ENGINEERING IN SOYBEAN}

As the consumption of isoflavones is associated with a variety of health benefits to the humans, several attempts were made to develop soybeans that accumulate much higher levels of isoflavones than in wild-type seed. Generally, the isoflavone contents in G. max (soybean) were improved through metabolic engineering of the complex phenylpropanoid biosynthetic pathway. In a first study, the phenylpropanoid pathway genes were activated by expressing the maize $C R C$ fusion gene, resulting in a decrease in genistein and the increase in daidzein levels with a marginal increase in total isoflavone levels (Grotewold et al., 1998). Cosuppression of flavanone 3-hydroxylase to block the anthocyanin branch of the pathway, in conjunction with CRC expression, resulted in higher levels of isoflavones (Yu et al., 2003). The use of transcription factor-driven gene activation combined with the suppression of a competing pathway resulted in increased isoflavone accumulation in soybean seeds. These high isoflavone soybeans could be used to make soy foods with greater health benefits to consumers.

The regulation of isoflavone biosynthesis is carried out by multiple genes and complex metabolic pathways. In order to understand the specific functions/regulation of the genes involved in the phenylpropanoid pathway for isoflavone biosynthesis, the overexpression or gene-silencing methods of specific genes can be carried out. Hence, Subramanian et al. (2005) have studied the RNAi-mediated gene silencing of GmIFS genes in the soybean. The study resulted in the reduced level of isoflavone accumulation in the gene silenced plants compared to control (Table 2). In another study, overexpression of CHS6 
TABLE 2 | Studies on the regulation of isoflavone biosynthesis in soybean.

\begin{tabular}{|c|c|c|c|c|}
\hline S. no. & Genes & Regulation & Results & References \\
\hline 1 & GmIFS & Positive regulation & $\begin{array}{l}\text { RNAi-mediated gene silencing reduced the level of } \\
\text { isoflavone content in the soybean }\end{array}$ & $\begin{array}{l}\text { Subramanian et al., } \\
2005\end{array}$ \\
\hline 2 & CHS6 and IFS2 & Negative regulation & $\begin{array}{l}\text { Transformed plants found reduced accumulation of } \\
\text { isoflavones and increased accumulation of phenolic } \\
\text { compounds }\end{array}$ & $\begin{array}{l}\text { Lozovaya et al., } \\
2007\end{array}$ \\
\hline 3 & GmMYB176 & Positive regulation & $\begin{array}{l}\text { No significant improvement in the overexpression but in } \\
\text { transient expression }\end{array}$ & Yi et al., 2010 \\
\hline 4 & GmFNSII & Negative regulation & $\begin{array}{l}\text { RNAi-mediated silencing increased the genistein level } \\
\text { significantly }\end{array}$ & Jiang et al., 2010 \\
\hline 5 & GmMYB39 & Negative regulation & $\begin{array}{l}\text { Overexpression reduced the transcript levels of } P A L, C 4 H \text {, } \\
\mathrm{CH} \text {, and } \mathrm{CHS} \text { genes }\end{array}$ & Liu et al., 2013 \\
\hline 6 & F3H and GmFNSII & Negative regulation & $\begin{array}{l}\text { RNAi-mediated silencing increased the daidzein and } \\
\text { genistein level significantly }\end{array}$ & Jiang et al., 2014 \\
\hline 7 & GmMYB100 & Negative regulation & $\begin{array}{l}\text { Overexpression reduced the transcript level, whereas } \\
\text { RNAi-mediated gene silencing increased the transcript level } \\
\text { of isoflavonoids genes }\end{array}$ & Yan et al., 2015 \\
\hline 8 & GmMYB29 & Positive regulation & $\begin{array}{l}\text { Overexpression increased the isoflavone level in 1.6- to } \\
\text { 3.3-fold, whereas RNAi gene silencing decreased the } \\
\text { isoflavone content in twofold }\end{array}$ & Chu et al., 2017 \\
\hline 9 & GmIMaT1 and GmIMaT3 & Positive regulation & $\begin{array}{l}\text { Overexpression significantly increased the level of isoflavone } \\
\text { aglycones, glucosides. and malonylates, whereas } \\
\text { knockdown the genes reduced the contents }\end{array}$ & Ahmad et al., 2017 \\
\hline 10 & GmMYBJ3 & Positive regulation & $\begin{array}{l}\text { Activates } \mathrm{CHS} 8 \text { and } \mathrm{CH} 1 \mathrm{~A} \text { and increases the accumulation } \\
\text { of isoflavones }\end{array}$ & Zhao et al., 2017 \\
\hline 11 & $\begin{array}{l}\text { Gma-miRNA12, Gma-miRNA24, } \\
\text { Gma-miRNA26, Gma-miRNA28, and } \\
\text { Gma-miRNA29 }\end{array}$ & Positive regulation & $\begin{array}{l}\text { Corresponding genes for the Gma-miRNA26, } \\
\text { Gma-miRNA28 have increased the isoflavone content in } \\
\text { soybean }\end{array}$ & Gupta et al., 2017 \\
\hline 12 & $\mathrm{GmCHI} A \mathrm{~A}$ & Positive regulation & $\begin{array}{l}\text { Overexpression of } \mathrm{CH} / 1 \mathrm{~A} \text { leads to the increased } \\
\text { accumulation of daidzein in transgenic plants }\end{array}$ & Zhou et al., 2018 \\
\hline 13 & GmMYB133 & Positive regulation & $\begin{array}{l}\text { Increased the transcript level of GmIFS2 and GmCHS8 also } \\
\text { increased the total isoflavone contents in the hairy roots }\end{array}$ & Bian et al., 2018 \\
\hline 14 & $\begin{array}{l}\text { GmMYB102, GmMYB280, and } \\
\text { GmMYB502 }\end{array}$ & Positive regulation & $\begin{array}{l}\text { Two- to fourfold increased accumulation of isoflavones was } \\
\text { found }\end{array}$ & Sarkar et al., 2019 \\
\hline 15 & GmMYB176 & Positive regulation & $\begin{array}{l}\text { Activating CHS8 gene and identified } 25 \text { metabolic genes } \\
\text { and six metabolites upon overexpression }\end{array}$ & $\begin{array}{l}\text { Anguraj Vadivel } \\
\text { et al., } 2019\end{array}$ \\
\hline 16 & $\mathrm{GmF} 3 \mathrm{H} 1, \mathrm{GmF} 3 \mathrm{H} 2$, and GmFNSII-1 & Positive regulation & $\begin{array}{l}\text { CRISPR/Cas9-mediated targeted gene editing leads to the } \\
\text { increased accumulations of isoflavones }\end{array}$ & Zhang et al., 2020 \\
\hline 17 & GmMYB29A2 & Positive regulation & $\begin{array}{l}\text { Overexpression increased glyceollin accumulation and RNAi } \\
\text { gene silencing decreased the accumulation. Accumulation } \\
\text { of glyceollin leads to the resistance to Phytophthora sojae }\end{array}$ & Jahan et al., 2020 \\
\hline 18 & $\mathrm{GmCH} / 1 \mathrm{~A}$ & Positive regulation & $\begin{array}{l}\mathrm{T}_{2} \text { transgenic plants accumulated the higher level of } \\
\text { genistein and daidzein than the control plants }\end{array}$ & Nguyen et al., 2020 \\
\hline 19 & GmMYB176 & Positive regulation & $\begin{array}{l}\text { Improved the accumulation of isoflavone biosynthetic genes } \\
\text { based on the diurnal regulation system }\end{array}$ & $\begin{array}{l}\text { Matsuda et al., } \\
2020\end{array}$ \\
\hline 20 & GmMYB176 and GmbZIP5 & Positive regulation & $\begin{array}{l}\text { Enhance accumulation of multiple isoflavonoid } \\
\text { phytoalexins, namely, glyceollin, isowighteone, and } \\
\text { O-methyl hydroxyl isoflavone in soybean hairy roots }\end{array}$ & Vadivel et al., 2021 \\
\hline
\end{tabular}

and IFS2 genes resulted in the reduced level of isoflavones and increased level of phenolic compounds (Lozovaya et al., 2007). Jiang et al. $(2010 ; 2014)$ explored the negative regulation of F3H and GmFNSII genes by the RNAi-mediated gene silencing studies. Previously, the gene silencing of GmFNSII resulted in the increased accumulation of genistein in soybean hairy roots (Jiang et al., 2010). Later, RNAi-mediated silencing of both genes ( $F 3 H$ and GmFNSII) was found to increase accumulation of isoflavones such as daidzein and genistein (Jiang et al., 2014) (Table 2).
Overexpression of GmIMaT1, GmIMaT3 genes significantly increased the different forms of isoflavones such as aglycones, glucosides, and malonylates, but in knockdown of the genes, the isoflavone levels were reduced drastically (Ahmad et al., 2017) (Table 2). Zhang et al. (2020) have used a new methodology for the regulation of isoflavone biosynthetic genes by introducing CRISPR/Cas9-mediated targeting mutation of multiple genes $(G m F 3 H 1, G m F 3 H 2$, and GmFNSII-1) in soybean. The T3 generation of triple gene mutants produced increased levels (twice the amount) of genistein compared to controls. The 
increased isoflavone content also leads to the enhanced resistance to soybean mosaic virus infections (Zhang et al., 2020). Recently, Nguyen et al. (2020) found that overexpression of GmCHI1A was found to increase higher levels of both genistein and daidzein in T2 generations, but previously, Zhou et al. (2018) reported that it can increase the daidzein content alone (Table 2).

Not only changing the specific genes in the phenylpropanoid pathway can notably increase/decrease isoflavone content but also the transcription factors. Therefore, the identification and application of transcription factors, particularly for the isoflavone pathway, may significantly resolve this problem (Yu and McGonigle, 2005; Chu et al., 2017). The transcription factors of the Myeloblastosis (MYB) family play crucial roles in the regulation of isoflavone biosynthesis. Yi et al. (2010) demonstrated through the functional genomic approach that GmMYB176 (R1 MYB protein) regulates CHS8 expression and affects the synthesis of isoflavonoids in soybean. In this study, cotransfection analysis with Arabidopsis leaf protoplast resulted that GmMYB176 transactivate the CHS8 promoter with maximum activity. As a result of transient expression in soybean embryo protoplast, after $48 \mathrm{~h}$, the endogenous transcript levels were increased up to 149 -fold. Subcellular localization assay indicates that GmMYB176 is a nuclear protein. RNAi-mediated gene silencing of GmMYB176 in hairy roots resulted in reduced levels of isoflavonoids, but overexpression of GmMYB176 did not significantly increase the levels of CHS8 transcript (Yi et al., 2010) (Table 2). Liu et al. (2013) reported that soybean MYB transcription factor $G m M Y B 39$ was potentially regulating the isoflavone biosynthesis. GmMYB39 that contained N-terminal R2R3 repeats corresponds to DNA-binding domains of plant MYB-type proteins, which were highly conserved among R2R3MYB proteins. Quantitative reverse transcriptase-polymerase chain reaction results revealed that overexpression of GmMYB39 was found to be varied in different parts of the plants. Interestingly, the higher level of transcripts was found in flowers, and lower level in the pods. GmMYB39 overexpression in hairy roots resulted in drastic reduction of the transcript levels of $P A L, C 4 H, C H S, 4 C L$, and CHR. However, the transcript level of IFS was slightly increased, whereas there is no change in $\mathrm{CHI}$ expression between overexpressed hairy roots and control roots. Overall, this report suggests that GmMYB39 is involved in the inhibition role in regulation of isoflavone biosynthesis in soybean (Table 2).

Yan et al. (2015) found that R2R3-MYB transcription factor GmMYB100 is involved in soybean isoflavone biosynthesis. Generally, GmMYB100 is expressed in flowers, leaves, and immature embryo, but its level will decrease after pod ripening. The subcellular localization study found the nuclear localization of GmMYB100. Initially, yeast functional assay revealed the transactivation ability of GmMYB100, but the bioinformatics analyses suggested its negative role in flavonoid biosynthesis. Finally, the overexpression of GmMYB100 reduced transcript levels of transgenic hairy roots and Arabidopsis and reduced flavonoid and flavonol productions, respectively, whereas the RNAi-mediated silencing resulted in the higher level of transcripts of six flavonoid related genes and accumulated higher level of flavonoids in transgenic hairy roots (Table 2).
Similarly, Genome-Wide Association Study for the identification of SNPs related to isoflavone concentration in soybean found that another R2R3-MYB transcription factor GmMYB29 is significantly involved in regulation of isoflavone biosynthesis (Chu et al., 2017). The subcellular localization analysis found that GmMYB29 was located in the nucleus. It is found to be activated IFS 2 and CHS 8 gene promoters by the transient gene expression assays. Furthermore, GmMYB29 overexpression and RNAi-mediated silencing in soybean hairy roots resulted in 1.6to 3.3-fold increase and isoflavone contents in twofold decrease (Chu et al., 2017). Zhao et al. (2017) explored the role of $G m M Y B J 3$ in regulation of the isoflavone biosynthetic pathway. This result suggests that GmMYBJ3 can activate the CHS8 and CHI1A genes; therefore, increased accumulation of isoflavones has been witnessed (Zhao et al., 2017).

Gupta et al. (2017) have identified miRNAs in the regulation of isoflavone biosynthesis in two contrast genotypes of soybean. In silico analysis identified 31 new miRNAs along with the 245 putative target genes from the seed-specific ESTs. Based on the Kyoto Encyclopedia of Genes and Genomes pathway analyses, five genes (Gma-miRNA12, Gma-miRNA24, GmamiRNA26, Gma-miRNA28, and Gma-miRNA29) were found to be involved in isoflavone biosynthesis, among which GmamiRNA26 and Gma-miRNA28 and their corresponding genes (Glyma.10G197900 and Glyma.09G127200) exhibited their direct relationship with the isoflavone content of the soybean (Table 2). Bian et al. (2018) identified that GmMYB133 (CCA1-like MYB) positively regulates isoflavone biosynthesis in soybean. Overexpression of GmMYB133 has led to the expression of two important isoflavonoid biosynthetic genes such as GmIFS2 and GmCHSs and increased total isoflavonoid contents in the hairy roots. Furthermore, the protein-protein interaction results revealed that it can form heterodimers with another isoflavone regulator GmMYB176 and homodimers with another GmMYB133 (Bian et al., 2018).

Sarkar et al. (2019) found that GmMYB102, GmMYB280, and $G m M Y B 502$ were the potential transcription factors that can activate the promoters of the CHS gene ( $G m C H S 8)$ and the IFS genes (GmIFS1 and GmIFS2) in the isoflavone biosynthetic pathway by hairy root transformation assay. They have assessed the functional regulatory role of these genes by hairy root transformation assay, resulting in increased accumulation of isoflavones (two- to fourfold) in the three MYB overexpressing lines compared to vector control (Table 2). Anguraj Vadivel et al. (2019) have identified that GmMYB176 (R1 MYB transcription factor) activates the CHS8 gene and regulates the isoflavonoid biosynthesis in soybean. They have identified 25 metabolic genes and six metabolites by the targeting approach that is differentially regulated during overexpression and silencing of GmMYB176 in soybean hairy roots (Table 2 ).

Jahan et al. (2020) have identified that GmMYB29A2 transcription factor positively regulates glyceollin biosynthesis in soybean. Glyceollins are pathogen-inducible defensive metabolites (phytoalexins) that play important roles in pathogen defense (Jahan et al., 2019). Overexpression of GmMYB29A2 increased the expression of GmNAC42-1, GmMYB29A1, and glyceollin biosynthesis genes and metabolites, whereas 
RNAi-mediated gene silencing had opposite effects. Previously, Jahan et al. (2019) have studied the role of GmNAC42-1 in activation of glyceollin biosynthesis by expression analysis. In this study, they confirmed the positive regulation of GmMYB29A2 that leads to the increased conversion of isoflavonoids into the glyceollin and thus develops resistance against Phytophthora sojae (Jahan et al., 2020). Matsuda et al. (2020) studied the diurnal metabolic regulation of isoflavones and soy saponins in soybean roots. The transcriptome and metabolite analysis of soybean plants at 6-h intervals for $48 \mathrm{~h}$ in a 12-h light-12-h dark condition. In the root tissues, isoflavone and soy saponin biosynthetic genes showed opposite patterns; the former are highly expressed in the day, whereas the latter are strongly triggered at night. GmMYB176, which encodes an isoflavone biosynthesis transcription factor, was upregulated from ZT0 (6:00 A.M.) to ZT6 (12:00 A.M.), accompanied by the stimulation of isoflavone biosynthetic genes at ZT6 (Matsuda et al., 2020). Recently, Vadivel et al. (2021) have found that the RNAi silencing of transcription factor GmbZIP5 reduced the isoflavone accumulation in hairy roots. Furthermore, the co-overexpression of GmMYB176 and GmbZIP5 enhanced the accumulation of multiple isoflavonoids such as glyceollin, malonyl glycitin, isowighteone, and $O$-methyl hydroxyl isoflavone in soybean hairy roots. An ample of studies in the regulation of isoflavone biosynthetic genes provided the role of key players in soybean isoflavone biosynthesis, which could be useful for the development of soybean with desired level of isoflavones.

\section{METABOLIC ENGINEERING OF ISOFLAVONE IN NONSOYBEAN CROPS}

Epidemiologic studies show that a high intake of soybean-derived foods is linked to a low incidence of hormone-related cancers, menopausal symptoms, osteoporosis, menopausal symptoms, and cardiovascular diseases. Furthermore, metabolic engineering of isoflavonoids in common nonlegume vegetables, grains, and fruits to increase dietary intake of these compounds has piqued researchers' interest (Dixon and Sumner, 2003; McCue and Shetty, 2004; Deavours and Dixon, 2005).

Initially, in a monocot cell system, introduced expression of a transcription factor controlling anthocyanin pathway genes was successful in the production of genistein in the presence of the IFS gene (Yu et al., 2000). The genistein produced in tobacco, Arabidopsis, and maize cells is present in conjugated forms, indicating that endogenous enzymes were capable of recognizing genistein as a substrate. Introducing foreign IFS gene in Arabidopsis seedlings (Jung et al., 2000), tobacco petals, and maize cells in which the phenylpropanoid pathway was activated by $\mathrm{C} 1$ and $\mathrm{R}$ transcription factors resulted in successful accumulation of genistein (Yu et al., 2000), demonstrating that heterogeneous IFS can use flavanone intermediates as substrates. However, in these cases, the genistein levels were two- to threefold lesser than in soybean seeds (Dixon and Ferreira, 2002). The higher genistein content in transgenic tobacco petals compared to leaves was thought to be due to a more active phenylpropanoid pathway leading to anthocyanin biosynthesis in petals, which also increased the level of intermediates available to IFS ( $Y u$ et al., 2000). The low transgene expression is not the cause of low genistein production in the tobacco leaves. The IFS mRNA was actually detected at a higher level in the leaves than in the flowers of tobacco transformants, and IFS protein and enzyme activity were also confirmed in the leaves. Thus, the poor genistein synthesis is most likely due to a lack of naringenin substrate. As IFS can fight for naringenin in tobacco flowers and Arabidopsis leaves, channeling might be the cause of unavailability.

Conversely, Liu et al. (2002) produced transgenic Arabidopsis with significantly increased genistein accumulation (31$169 \mathrm{nmol} / \mathrm{g}$ Fresh weight (FW)), but soybean IFS was introduced into Arabidopsis tt6/tt3 mutant in which the expression of $\mathrm{F} 3 \mathrm{H}$ and another flavonol/anthocyanin enzyme dihydroflavonol reductase was decreased (Liu et al., 2002). As F3H and IFS both use naringenin as a substrate, the researchers hypothesized that the competition for intermediate availability between IFS and other enzymes was a limiting factor for a genistein biosynthesis in genetically modified plants. Furthermore, blocking a competing branch pathway may be a useful method to promote genistein biosynthesis (Liu et al., 2007). UV-B irradiation of Arabidopsis transformants expressing the soybean IFS gene resulted in a 2.5fold increase in genistein accumulation. Increased levels of UV absorption and anthocyanins in IFS-transformed plants depict the higher activity of phenylpropanoid pathway (Yu et al., 2000; Liu et al., 2002). Deavours and Dixon (2005) have improved the genistein production for up to $50 \mathrm{nmol} / \mathrm{g} \mathrm{FW}$ by constitutively expressing MtIFS1 in the alfalfa plants. Genistein levels of this study are much higher than previous studies (Jung et al., 2000; Yu et al., 2000; Liu et al., 2002). Even though MtIFS1 expresses all the tissues in plants, genistein accumulation was specific to the leaves. Apart from the genistein, the plants also accumulated other isoflavones such as daidzein and formononetin in response to the UV-B treatments.

Tian and Dixon (2006) have improved the isoflavone metabolism by introducing the $\mathrm{CHI}, \mathrm{CHS}$, and $\mathrm{CHI} / \mathrm{CHS}$ fusion protein into the tobacco plants. High-performance liquid chromatography (HPLC) analysis results showed the accumulation of genistein in both IFS- and IFS/CHI-transformed plants, but not in vector control and $\mathrm{CHI}$ plants. In transgenic tobacco, lettuce, and petunia, both overexpression and antisense suppression were used to control the expression of multiple genes essential enzymes in the flavonoids/isoflavonoids pathway (Liu et al., 2007) (Table 1). The introduction of soybean IFS (GmIFS) into these plants, which lack this leguminous enzyme and therefore do not produce isoflavonoids naturally, resulted in genistein biosynthesis in tobacco petals, petunia leaves and petals, and leaves of lettuce. In tobacco, when antisense suppression of $\mathrm{F} 3 \mathrm{H}$ and overexpression of GmIFS were done simultaneously, the yield of genistein increased prominently. In addition, overexpression of PAL also led to an enhanced genistein production in tobacco petals and lettuce leaves in the presence of IFS than in the plants that overexpressed only IFS (Liu et al., 2007). Similarly, Misra et al. (2010) transformed the IFS gene from the medicinal plant $P$. corilyfolia (PcIFS) into the tobacco. 
Overexpression of PcIFS resulted in the higher accumulation of isoflavones in the tobacco petals (Table 1).

As rice is an important crop and staple food for half of the world population, recently it caught extensive attention as bioreactors for the production of therapeutic compounds and proteins. Although production of isoflavones in rice plants was performed by several researchers, Shin et al. (2006) for the first time in rice plants have transformed maize $C 1$ and $R-S$ regulatory genes for the production of isoflavones. The expression of transgenes is restricted to endosperm under the control of a rice prolamin gene promoter. The transformed plants showed several phenotypic variations such as changes in pericarp color, chalky endosperm, and opaque kernel. HPLC analysis showed that several types of isoflavones accumulated in the transgenic kernels. Among which taxifolin, 3'-Omethyl taxifolin and $3^{\prime}$-O-methyl quercetin were identified through liquid chromatography (LC)-tandem mass spectrometry (MS/MS) analysis (Table 1). Furthermore, they have confirmed the accumulation of isoflavones in the layers of endosperm by the florescence labeling. At the same time, Sreevidya et al. (2006) have introduced the GmIFS gene into the rice plants for the production of isoflavones under the control of CaMV35S promoter. The genistein accumulated as a glycosylated form in the rice plants. Rhizobia study for the nod gene expression confirms the accumulation of isoflavones inducing the nod genes in varied degrees.

Introduction of five biosynthetic genes (OsPAL, OsC4H, $\mathrm{Os} 4 \mathrm{CL}$, OsCHS, and $\mathrm{OsCHI}$ ) with the endosperm-specific GluB-1 promoter into one vector has been done through Agrobacteriummediated transformation (Ogo et al., 2013). As multipleexpression cassette is quite large, some of the parts were deleted in a few plants; as a result, none of the transgenic plants did not express all the five genes. Generally, plants were found to have one to four expression cassettes. The resulted plant that is lacking either OsPAL or OsCHS gene does not accumulate naringenin, but has both genes accumulating naringenin in the seeds. Furthermore, these selected genes were transformed exclusively with embryo- and endosperm-specific $18 \mathrm{kDa}$ oleosin and GluB1 promoters for the identification of isoflavone localization. LC-MS analysis revealed the accumulation of naringenin and some flavones. Also the expression of additional genes for flavone (PoFNSI/GmFNSII), isoflavone (GmIFS), and flavonol (AtF3H/AtFLS) has resulted in the accumulation of kaempferol, genistein derivatives, quercetin, chrysoeriol, and tricin, etc. (Table 1). Song et al. (2013) aimed to generate colored rice seeds and increased accumulation of isoflavone that expressed maize-Lc gene under the control of endosperm-specific rice glutelin Gt-1 promoter. As a result, the transgenic rice was found to be with dark color and the total isoflavone content also increased. Expression of two soybean isoflavone synthases (SpdIFS1 and SpdIFS2) under the control of endosperm-specific 26-kDa globulin promoter in rice varieties accumulated a higher level of genistein in seeds (Sohn et al., 2014). As the two rice varieties has different seed color (black and normal white), the accumulation of isoflavone was also found to be varied. The white variety $(103 \mu \mathrm{g} / \mathrm{g})$ of transgenic rice has accumulated more genistein than black variety $(87 \mu \mathrm{g} / \mathrm{g})$ (Table $\mathbf{1})$.
In an attempt of isoflavone biosynthesis in tomato, Shih et al. (2008) have transformed soybean IFS (GmIFS) gene under the control of the CaMV35S promoter. The transgenic plants accumulated genistein in a tissue-specific manner. The LCMS analysis has found that substantial amount of genistein has been accumulated in the leaves, whereas the little amount has been accumulated in fruit peel. Although Brassica napus, a nonleguminous oil crop, produced phenylpropanoids and flavonoids but not isoflavones because of the absence of the IFS gene. Incorporation of exogenous GmIFS2 showed the accumulation of genistein in the leaves of transgenic plants up to $0.72 \mathrm{mg} / \mathrm{g}$ dry weight (Li et al., 2011) (Table 1). With the aim of increased accumulation of genistein in transgenic tobacco, Pandey et al. (2014) has engineered the tobacco with the coexpression of GmIFS and transcription factor AtMYB12. The transgenic plants accumulated higher levels of flavonols and genistein conjugates compared to control plants. Gou et al. (2016) have transformed different combinations of isoflavone pathway genes (CHS, CHI, IFS, and F3H) in Medicago truncatula for the increased accumulation of isoflavones and proanthocyanidins. Downregulation of $\mathrm{MtF3H}$ in combination with overexpression of GmIFS1, GmCHS7, and GmCHI1A was found to be more effective in elevated accumulation of isoflavones, flavones, and proanthocyanidins. Recently, Malla et al. (2021) have transformed GmIFS into onion (Allium cepa L.) for the accumulation of genistein in transformed onion plants through both biolistic gene transfer and Agrobacterium-mediated gene transfer methods. The results showed that a higher level of genistein was accumulated in biolistic gene transfer $(62.65 \mathrm{nM} / \mathrm{g}$ FW) than Agrobacterium-mediated gene transfer method. Thus, introducing the transcription factor for the positive or negative regulation of the isoflavone biosynthesis proved the efficiency of transcription factors, suggesting that it can be utilized for both leguminous and nonleguminous plants for the regulation of isoflavone biosynthesis.

\section{CONCLUDING REMARKS AND FUTURE PROSPECTS}

Isoflavones have important roles in plants, environment, humans, and other animals with their compatible chemical structures. Their general occurrence in the soybean and its applications in various diseases, as we highlighted, necessitated the detailed understanding of the metabolic engineering process and the regulation of isoflavone biosynthesis in the plants. We have provided an overview of the isoflavone biosynthesis through metabolic engineering in various crop plants. The recent progression in the identification and characterization of important enzymes in the isoflavone biosynthetic pathway has helped to improve the level of isoflavones in plants. However, as phenylpropanoid pathway is a complex pathway for isoflavone biosynthesis, simultaneous engineering of multiple genes and understanding the crosstalk between pathways are important. That helps us to understand the role of a specific branch of the pathway in the biosynthesis of isoflavones and other secondary metabolites. The isoflavone-level variation 
is a complex mechanism regulated by various genetic and environmental factors. Transcriptional regulation of isoflavone biosynthesis occurs by modifying the transcription factors such as MYBs either to increase or decrease the level of isoflavones in soybean (Yi et al., 2010; Yan et al., 2015; Bian et al., 2018; Jahan et al., 2020). In addition to that, posttranslational regulation of isoflavone biosynthesis through ubiquitination and SUMOylation processes has become necessary tools for clear understanding of how isoflavones can be produced. Likewise, synthetic metabolic engineering technologies, such as a multigene expression vector system (CRISPR/cas9)-based system, should be used efficiently for expression and regulation of isoflavone biosynthetic genes in a precise manner (Zhang et al., 2020). With the deep understanding of the isoflavone biosynthetic pathway, novel technologies in metabolic engineering and synthetic metabolic engineering will decipher light on the regulation of complex metabolic networks and can produce

\section{REFERENCES}

Abdel-Lateif, K., Bogusz, D., and Hocher, V. (2012). The role of flavonoids in the establishment of plant roots endosymbioses with arbuscular mycorrhiza fungi, rhizobia and Frankia bacteria. Plant Signal. Behav. 7, 636-641. doi: 10.4161/psb. 20039

Abdi, F., Alimoradi, Z., Haqi, P., and Mahdizad, F. (2016). Effects of phytoestrogens on bone mineral density during the menopause transition: a systematic review of randomized, controlled trials. Climacteric 19, 535-545. doi: 10.1080/ 13697137.2016.1238451

Ahmad, M. Z., Li, P., Wang, J., Rehman, N. U., and Zhao, J. (2017). Isoflavone malonyltransferases GmiMaT1 and GmiMaT3 differently modify isoflavone glucosides in soybean (Glycine max) under various stresses. Front. Plant Sci. 8:735. doi: 10.3389/fpls.2017.00735

Ahmad, M. Z., Zhang, Y., Zeng, X., Li, P., Wang, X., Benedito, V. A., et al. (2020). Isoflavone malonyl-CoA acyltransferase GmMaT2 is involved in nodulation of soybean (Glycine max) by modifying synthesis and secretion of isoflavones. J. Exp. Bot. 101, 106-109. doi: 10.1093/jxb/ eraa511

Akashi, T., Aoki, T., and Ayabe, S. (1999). Cloning and functional expression of a cytochrome P450 cDNA encoding 2-hydroxyisoflavanone synthase involved in biosynthesis of the isoflavonoid skeleton in licorice. Plant Physiol. 121, 821-828. doi: 10.1104/pp.121.3.821

Akashi, T., Aoki, T., and Ayabe, S. (2005). Molecular and biochemical characterization of 2-hydroxyisoflavanone dehydratase. Involvement of carboxylesterase-like proteins in leguminous isoflavone biosynthesis. Plant Physiol. 13, 882-891. doi: 10.1104/pp.104.05 6747

Anguraj Vadivel, A. K., Renaud, J., Kagale, S., and Dhaubhadel, S. (2019). GmMYB176 regulates multiple steps in isoflavonoid biosynthesis in soybean. Front. Plant Sci. 10:562. doi: 10.3389/fpls.2019.00562

Appert, C., Logemann, E., Hahlbrock, K., Schmid, J., and Amrhein, N. (1994). Structural and catalytic properties of the four phenylalanine ammonia-lyase isozymes from parsley (Petroselinum crispum Nym.). Eur. J. Biochem. 225, 491-499. doi: 10.1111/j.1432-1033.1994.00 491.x

Atcharaporn, K., Thawunporn, P., and Lamsal, B. (2014). "Isoflavones-extraction and bioavailability," in Functional Foods and Dietry Supplements, eds A. K. Anal, A. Noomhorm, and I. Ahmad (Hoboken, NJ: Wiley), 255-293. doi: 10.10002/ 9781118227800.ch10

Ayabe, S.-I., Udagawa, A., and Furuya, T. (1988). NAD(P)H-dependent 6'deoxychalcone synthase activity in Glycyrrhiza echinata cells induced by yeast extract. Arch. Biochem. Biophys. 261, 458-462. doi: 10.1016/0003-9861(88) 90362- 1 biofortified crops with required isoflavone levels to meet better human health.

\section{AUTHOR CONTRIBUTIONS}

SIS and SP conceived the review and wrote the manuscript and made a critical revision of the review. YJO, HJK, WSC, and YSC performed the literature search. SP and YJO prepared figures and tables. All authors contributed to the article and approved the submitted version.

\section{FUNDING}

This work was supported by a grant from the New Breeding Technologies Development Program (Project No. PJ01492902), Rural Development Administration, Republic of Korea.

Ballance, G. M., and Dixon, R. A. (1995). Medicago sativa cDNAs encoding chalcone reductase. Plant Physiol. 107:1027. doi: 10.1104/pp.107.3. 1027

Bate, N. J., Orrt, J., Nit, W., Meromit, A., Nadler-hassar, T., Doerner, P. W., et al. (1994). Quantitative relationship between phenylalanine ammonia-lyase levels and phenylpropanoid accumulation in transgenic tobacco identifies a ratedetermining step in natural product synthesis. Proc. Natl. Acad. Sci. U.S.A. 91, 7608-7612. doi: 10.1073/pnas.91.16.7608

Bian, S., Li, R., Xia, S., Liu, Y., Jin, D., Xie, X., et al. (2018). Soybean CCA1-like MYB transcription factor GmMYB133 modulates isoflavonoid biosynthesis. Biochem. Biophys. Res. Commun. 507, 324-329. doi: 10.1016/j.bbrc.2018.11.033

Burdick, A. B. (1958). New mutants. Tomato Genet. Coop. Rep. 8, 9-11.

Caetano-Anolles, G., Wrobel-Boerner, E., and Bauer, W. D. (1992). Growth and movement of spot inoculated Rhizobium meliloti on the root surface of alfalfa. Plant Physiol. 98, 1181-1189. doi: 10.1104/pp.98.3.1181

Chapple, C. (1998). Molecular-genetic analysis of plant cytochrome P450dependent monooxygenases. Ann. Rev. Plant. Physiol. Plant. Mol. Biol. 49, 311-343. doi: 10.1146/annurev.arplant.49.1.311

Chen, L. R., Ko, N. Y., and Chen, K. H. (2019). Isoflavone supplements for menopausal women: a systematic review. Nutrients 11:2649. doi: 10.3390/ nu11112649

Cheng, H., Li, L., Cheng, S., Cao, F., Wang, Y., and Yuan, H. (2011). Molecular cloning and function assay of a chalcone isomerase gene (GbCHI) from Ginkgo biloba. Plant Cell Rep. 30, 49-62. doi: 10.1007/s00299-010-0943-4

Cheng, S. Y., Wang, Y., Liu, W. H., Du, H. W., and Chen, K. S. (2005). Effects of plant growth regulators on phenylalanine ammonia-lyase (PAL) activities in leaves of Ginkgo biloba. J. Plant Res. Environ. 14, 20-22.

Chi, X. X., Zhang, T., Zhang, D. J., Yu, W., Wang, Q. Y., and Zhen, J. L. (2016). Effects of isoflavones on lipid and apolipoprotein levels in patients with type 2 diabetes in Heilongjiang Province in China. J. Clinical Biochem. Nutr. 59, 134-138. doi: 10.3164/jcbn.15-147

Chu, S., Wang, J., Zhu, Y., Liu, S., Zhou, X., Zhang, H., et al. (2017). An R2R3type MYB transcription factor, GmMYB29, regulates isoflavone biosynthesis in soybean. PLoS Genet. 13:e1006770. doi: 10.1371/journal.pgen.1006770

Cohen-Gonsaud, M., Ducasse, S., Hoh, F., Zerbib, D., Labesse, G., and Quemard, A. (2002). Crystal structure of MabA from Mycobacterium tuberculosis, a reductase involved in long-chain fatty acid biosynthesis. J. Mol. Biol. 320, 249-261. doi: 10.1016/S0022-2836(02)00463-1

Compton, K. K., Hildreth, S. B., Helm, R. F., and Scharf, B. E. (2020). An updated perspective on Sinorhizobium meliloti chemotaxis to alfalfa flavonoids. Front. Microbiol. 11:581482. doi: 10.3389/fmicb.2020.581482

Cui, Y., Niu, K., Huang, C., Momma, H., Guan, L., Kobayashi, Y., et al. (2015). Relationship between daily isoflavone intake and sleep in Japanese adults: a cross-sectional study. Nutr. J. 14, 1-7. doi: 10.1186/s12937-015-0117-x 
Daily, J. W., Ko, B. S., Ryuk, J., Liu, M., Zhang, W., and Park, S. (2019). Equol decreases hot flashes in postmenopausal women: a systematic review and metaanalysis of randomized clinical trials. J. Med. Food. 22, 127-139. doi: 10.1089/ jmf.2018.4265

Deavours, B. E., and Dixon, R. A. (2005). Metabolic engineering of isoflavonoid biosynthesis in alfalfa. Plant Physiol. 138, 2245-2259. doi: 10.1104/pp.105. 062539

Del Cerro, P., Megías, M., López-Baena, F. J., Gil-Serrano, A., Pérez-Montaño, F., and Ollero, F. J. (2019). Osmotic stress activates nif and fix genes and induces the Rhizobium tropici CIAT 899 Nod factor production via NodD2 by upregulation of the nodA2 operon and the nodA3 gene. PLoS One 14:e0213298. doi: 10.1371/journal.pone.0213298

Dhaubhadel, S., Gijzen, M., Moy, P., and Farhangkhoee, M. (2007). Transcriptome analysis reveals a critical role of CHS7 and CHS8 genes for isoflavonoid synthesis in soybean seeds. Plant Physiol. 143, 326-338. doi: 10.1104/pp.106. 086306

Dhaubhadel, S., McGarvey, B. D., Williams, R., and Gijzen, M. (2003). Isoflavonoid biosynthesis and accumulation in developing soybean seeds. Plant Mol. Biol. 53, 733-743. doi: 10.1023/B:PLAN.0000023666.30358.ae

Dixon, R. A., and Ferreira, D. (2002). Molecules of interest, genistein. Phytochemistry 60, 205-211. doi: 10.1016/S0031-9422(02)00116-4

Dixon, R. A., and Paiva, N. L. (1995). Stress-induced phenylpropanoid metabolism. Plant Cell. 93, 385-392. doi: 10.1105/tpc.7.7.1085

Dixon, R. A., and Steele, C. L. (1999). Flavonoids and isoflavonoids a gold mine for metabolic engineering trends. Plant Sci. 4, 394-400. doi: 10.1016/s13601385(99)01471-5

Dixon, R. A., and Sumner, L. W. (2003). Legume natural products: understanding and manipulating complex pathways for human and animal health. Plant Physiol. 131, 878-885. doi: 10.1104/pp.102.017319

Druka, A., Kudrna, D., Rostoks, N., Brueggeman, R., Von, W. D., and Kleinhofs, A. (2003). Chalcone isomerase from rice (Oryza sativa) and barley (Hordeum vulgare): physical, genetic and mutation mapping. Gene 302, 171-178. doi: 10.1016/S0378-1119(02)01105-1108

Du, H., Huang, Y., and Tang, Y. (2010). Genetic and metabolic engineering of isoflavonoid biosynthesis. Appl. Microbiol. Biotechnol. 86, 1293-1312. doi: 10. 1007/s00253-010-2512-8

Feinbaum, R. L., and Ausubel, F. M. (1988). Transcriptional regulation of the Arabidopsis thaliana chalcone synthase gene. Mol. Cell. Biol. 8, 1985-1992. doi: $10.1128 / \mathrm{mcb} .8 .5 .1985$

Fisher, R. F., and Long, S. R. (1992). Rhizobium-plant signal exchange. Nature 357, 655-660. doi: 10.1038/357655a0

Francini, A., Nali, C., Pellegrini, E., and Lorenzini, G. (2008). Characterization and isolation of some genes of the shikimate pathway in sensitive and resistant Centaurea jacea plants after ozone exposure. Environ. Pollut. 151, 272-279. doi: 10.1016/j.envpol.2007.07.007

Gaworzewska, E. T., and Carlile, M. J. (1982). Postive chemotaxis of Rhizobium leguminosarum and other bacteria towards root exudates from legumes and other plants. J. Gen. Microbiol. 128, 789-798. doi: 10.1099/00221287-128-61179

Geeta, G., Widodo, W. S., Widowati, W., Ginting, C. N., Lister, I. N. E., Armansyah, A., et al. (2019). Comparison of antioxidant and anti-collagenase activity of genistein and epicatechin. Pharm. Sci. Res. 6, 111-117. doi: 10.7454/psr.v6i2. 4510

Gilbert, E. R., and Liu, D. (2013). Anti-diabetic functions of soy isoflavone genistein: mechanisms underlying its effects on pancreatic $\beta$-cell function. Food. Funct.4, 200-212. doi: 10.1039/c2fo30199g

Given, N. K., Venis, M. A., and Gierson, D. (1988). Hormonal regulation of ripening in the strawberry, a non-climacteric fruit. Planta 174, 402-406. doi: $10.1007 /$ BF00959527

Graham, T. L. (1991). Flavonoid and isoflavonoid distribution in developing soybean seedling tissues and in seed and root exudates. Plant Physiol. 95, 594-603. doi: 10.1104/pp.95.2.594

Graham, T. L. (1995). "Cellular biochemistry of phenylpropanoid responses of soybean to infection by Phytophthora sojae," in Handbook of Phytoalexin Metabolism and Action, eds M. Daniel and R. P. Purkayanstha (New York, NY: Marcel Dekker), 85-116. doi: 10.1201/978020375 2647-5
Graham, T. L., Graham, M. Y., Subramanian, S., and Yu, O. (2007). RNAi silencing of genes for elicitation or biosynthesis of 5-deoxyisoflavonoids suppresses racespecific resistance and hypersensitive cell death in Phytophthora sojae infected tissues. Plant Physiol. 144, 728-740. doi: 10.1104/pp.107.097865

Grotewold, E., Chamberlin, M., Snook, M., Siame, B., Butler, L., Swenson, J., et al. (1998). Engineering secondary metabolism in maize cells by ectopic expression of transcription factors. Plant Cell. 10, 721-740. doi: 10.1105/tpc.10. 5.721

Guo, J., Zhou, W., Lu, Z., Li, H., Li, H., and Gao, F. (2015). Isolation and functional analysis of chalcone isomerase gene from purple-fleshed sweet potato. Plant Mol. Biol. Rep. 33, 1451-1463. doi: 10.1007/s11105-014-0842-x

Gou, L., Zhang, R., Ma, L., Zhu, F., Dong, J., and Wang, T. (2016). Multigene synergism increases the isoflavone and proanthocyanidin contents of Medicago truncatula. Plant Biotechnol. J. 14, 915-925. doi: 10.1111/pbi.12445

Gupta, O. P., Nigam, D., Dahuja, A., Kumar, S., Vinutha, T., Sachdev, A., et al. (2017). Regulation of isoflavone biosynthesis by miRNAs in two contrasting soybean genotypes at different seed developmental stages. Front. Plant Sci. 8:567. doi: $10.3389 /$ fpls.2017.00567

Hakamatsuka, T., Mori, K., Ishida, S., Ebizuka, Y., and Sankawa, U. (1998). Purification of 2-hydroxyisoflavanone dehydratase from the cell cultures of Pueraria lobata. Phytochemistry 49, 497-505. doi: 10.1016/S0031-9422(98) 00266-0

Hakamatsuka, T., Noguchi, H., Ebizuka, Y., and Sankawa, U. (1990). Isoflavone synthase from cell suspension cultures of Pueraria lobata. Chem. Pharm. Bull. 38, 1942-1945. doi: 10.1248/cpb.38.1942

Hayashi, H., Fujii, I., Iinuma, M., Shibano, M., Ozaki, K., and Watanabe, H. (2013). Characterization of a glycyrrhizin-deficient strain of Glycyrrhiza uralensis. Biol. Pharm. Bull. 36, 1448-1453. doi: 10.1248/bpb.b13-00164

He, X., Blount, J., Ge, S., Tang, Y., and Dixon, R. (2011). A genomic approach to isoflavone biosynthesis in kudzu (Pueraria lobata). Planta 233, 843-855. doi: 10.1007/s00425-010-1344-1

Holton, T. A., and Cornish, E. C. (1995). Genetics and biochemistry of anthocyanin biosynthesis. Plant Cell. 7:1071. doi: 10.1105/tpc.7.7.1071

Hooper, L., Madhavan, G., Tice, J. A., Leinster, S. J., and Cassidy, A. (2010). Effects of isoflavones on breast density in pre-and post-menopausal women: a systematic review and meta-analysis of randomized controlled trials. Hum. Reprod. Update 16, 745-760. doi: 10.1093/humupd/ dmq011

Hrazdina, G., Parsons, G. F., and Mattick, L. R. (1984). Physiological and biochemical events during development and maturation of grape berries. Am. J. Enol. Vitic. 35, 220-227.

Hrazdina, G., and Wagner, G. J. (1985). Metabolic pathways as enzyme complexes: evidence for the synthesis of phenylpropanoids and flavonoids on membrane associated enzyme complexes. Arch. Biochem. Biophys. 237, 88-100. doi: 10. 1016/0003-9861(85)90257-7

Hu, Y. S., Zhang, L., Di, P., and Chen, W. S. (2009). Cloning and induction of phenylalanine ammonia-lyase gene from Salvia miltiorrhiza and its effect on hydrophilic phenolic acids levels. Chin. J. Nat. Med. 7, 449-457. doi: 10.1016/ S1875-5364(09)60069-8

Hur, S., Newby, Z. E., and Bruice, T. C. (2004). Transition state stabilization by general acid catalysis, water expulsion, and enzyme reorganization in Medicago savita chalcone isomerase. Proc. Natl. Acad. Sci. U.S.A. 101, 2730-2735. doi: 10.1073/pnas.0308264100

Hyun, M. W., Yun, Y. H., Kim, J. Y., and Kim, S. H. (2011). Fungal and plant phenylalanine ammonia-lyase. Mycobiology. 39, 257-265. doi: 10.5941/MYCO. 2011.39.4.257

Iyer, B., and Rajkumar, S. (2017). Host specificity and plant growth promotion by bacterial endophytes. Curr. Res. Microbiol. Biotechnol. 5, 1018-1030.

Jahan, M. A., Harris, B., Lowery, M., Coburn, K., Infante, A. M., Percifield, R. J., et al. (2019). The NAC family transcription factor GmNAC42-1 regulates biosynthesis of the anticancer and neuroprotective glyceollins in soybean. BMC Genomics 20:149. doi: 10.1186/s12864-019-5524-5

Jahan, M. A., Harris, B., Lowery, M., Infante, A. M., Percifield, R. J., and Kovinich, N. (2020). Glyceollin transcription factor GmMYB29A2 regulates soybean resistance to Phytophthora sojae. Plant Physiol. 183, 530-546. doi: 10.1104/pp. 19.01293 
Jalili, M., Hekmatdoost, A., Vahedi, H., Poustchi, H., Khademi, B., Saadi, M., et al. (2016). Co-Administration of soy isoflavones and Vitamin D in management of irritable bowel disease. PLoS One 11:e0158545. doi: 10.1371/journal.pone. 0158545

Jeandet, P., Clement, C., Courot, E., and Cordelier, S. (2013). Modulation of phytoalexin biosynthesis in engineered plants for disease resistance. Intl. J. Mol. Sci. 14, 14136-14170. doi: 10.3390/ijms140714136

Jez, J. M., Bowman, M. E., Dixon, R. A., and Noel, J. P. (2000). Structure and mechanism of the evolutionarily unique plant enzyme chalcone isomerase. Nat. Struct. Biol. 7, 786-791. doi: 10.1038/79025

Jez, J. M., Bowman, M. E., and Noel, J. P. (2002). Role of hydrogen bonds in the reaction mechanism of chalcone isomerase. Biochemistry 41, 5168-5176. doi: 10.1021/bi0255266

Jez, J. M., and Noel, J. P. (2000). Mechanism of chalcone synthase. J. Biol. Chem. 275, 39640-39646. doi: 10.1074/jbc.M008569200

Jiang, Y., Hu, Y., Wang, B., and Wu, T. (2014). Bivalent RNA interference to increase isoflavone biosynthesis in soybean (Glycine max). Braz. Arch. Biol. Technol. 57, 163-170. doi: 10.1590/S1516-89132013005000018

Jiang, Y. N., Wang, B., Li, H., Yao, L. M., and Wu, T. L. (2010). Flavonoid production is effectively regulated by RNAi interference of two flavone synthase genes from Glycine max. J. Plant Biol. 53, 425-432. doi: 10.1007/s12374-0109132-9

Jorrin, J., and Dixon, R. A. (1990). Stress responses in alfalfa (Medicago sativa L.). Purification, characterization, and induction of phenylalanine ammonialyase isoforms from elicitor-treated cell suspension cultures. Plant Physiol. 92, 447-455. doi: 10.1104/pp.92.2.447

Jung, W., Yu, O., Lau, S. -M. C., O’Keefe, D. P., Odell, J., Fader, G., et al. (2000). Identification and expression of isoflavone synthase, the key enzyme for biosynthesis of isoflavones in legumes. Nat. Biotech 18, 208-212. doi: 10.1038/ 72671

Kang, J. H., McRoberts, J., Shi, F., Moreno, J. E., Jones, A. D., and Howe, G. A. (2014). The flavonoid biosynthetic enzyme chalcone isomerase modulates terpenoid production in glandular trichomes of tomato. Plant Physiol. 164, 1161-1174. doi: 10.1104/pp.113.233395

Kervinen, T., Peltonen, S., Utriainen, M., Kangasjärvi, J., Teeri, T. H., and Karjalainen, R. (1997). Cloning and characterization of cDNA clones encoding phenylalanine ammonia-lyase in barley. Plant Sci. 123, 143-150. doi: 10.1016/ S0168-9452(96)04570-0

Kochs, G., and Grisebach, H. (1986). Enzymic synthesis of isoflavones. Eur. J. Biochem. 155, 311-318. doi: 10.1111/j.1432-1033.1986.tb09492.x

Koes, R. E., Spelt, C. E., and Mol, J. N. (1989). The chalcone synthase multigene family of Petunia hybrida (V30): differential, light-regulated expression during flower development and UV light induction. Plant Mol. Biol. 12, 213-225. doi: 10.1007/BF00020506

Kraszewska, O., Nynca, A., Kaminska, B., and Ciereszko, R. (2007). Fitoestrogeny. 1. Wystepowanie, metabolizm i znaczenie biologiczne u samic. Postêpy Biol. Komórki 1, 189-205.

Kreuzaler, F., Ragg, H., Fautz, E., Kuhn, D. N., and Hahlbrock, K. (1983). UV-induction of chalcone synthase mRNA in cell suspension cultures of Petroselinum hortense. Proc. Natl. Acad. Sci. U.S.A. 80, 2591-2593. doi: 10.1073/ pnas.80.9.2591

Křrižová, L., Dadáková, K., Kašparovská, J., and Kašparovský, T. (2019). Isoflavones. Molecules 24:1076. doi: 10.3390/molecules24061076

Kumar, N. B., Cantor, A., Allen, K., Riccardi, D., and Cox, C. E. (2002). The specific role of isoflavones on estrogen metabolism in premenopausal women. Cancer 94, 1166-1174. doi: 10.1002/cncr.10320

Lepelley, M., Mahesh, V., McCarthy, J., Rigoreau, M., Crouzillat, D., Chabrillange, N., et al. (2012). Characterization, high-resolution mapping and differential expression of three homologous PAL genes in Coffea canephora Pierre (Rubiaceae). Planta 236, 313-326. doi: 10.1007/s00425-012-1613-2

Li, X., Qin, J. C., Wang, Q. Y., Wu, X., Lang, C. Y., Pan, H. Y., et al. (2011). Metabolic engineering of isoflavone genistein in Brassica napus with soybean isoflavone synthase. Plant Cell Rep. 30, 1435-1442. doi: 10.1007/s00299-0111052-8

Lim, W., and Li, J. (2016). Co-expression of onion chalcone isomerase in Del/Ros1-expressing tomato enhances anthocyanin and flavonol production. Plant Cell Tiss. Org. Cult. 128, 113-124. doi: 10.1007/s11240-0161090-6
Liu, C. J., Blount, J. W., Steele, C. L., and Dixon, R. A. (2002). Bottlenecks for metabolic engineering of isoflavone glycoconjugates in Arabidopsis. Proc. Nat. Acad. Sci. U.S.A 99, 14578-14583. doi: 10.1073/pnas.212522099

Liu, C. W., and Murray, J. D. (2016). The role of flavonoids in nodulation host-range specificity: an update. Plants 5:33. doi: 10.3390/plants5030033

Liu, R., Hu, Y., Li, J., and Lin, Z. (2007). Production of soybean isoflavone genistein in non-legume plants via genetically modified secondary metabolism pathway. Metab. Eng. 9, 1-7. doi: 10.1016/j.ymben.2006.08.003

Liu, R., Xu, S., Li, J., Hu, Y., and Lin, Z. (2006). Expression profile of a PAL gene from Astragalus membranaceus var. Mongholicus and its crucial role in flux into flavonoid biosynthesis. Plant Cell Rep. 25, 705-710. doi: 10.1007/s00299005-0072-7

Liu, X., Yuan, L., Xu, L., Xu, Z., Huang, Y., He, X., et al. (2013). Over-expression of GmMYB39 leads to an inhibition of the isoflavonoid biosynthesis in soybean (Glycine max. L). Plant Biotechnol. Rep. 7, 445-455. doi: 10.1007/s11816-0130283-2

Lozovaya, V. V., Lygin, A. V., Zernova, O. V., Li, S., Hartman, G. L., and Widholm, J. M. (2004). Isoflavonoid accumulation in soybean hairy roots upon treatment with Fusarium solani. Plant Physiol. Biochem. 42, 671-679. doi: 10.1016/j. plaphy.2004.06.007

Lozovaya, V. V., Lygin, A. V., Zernova, O. V., Ulanov, A. V., Li, S., Hartman, G. L., et al. (2007). Modification of phenolic metabolism in soybean hairy roots through down regulation of chalcone synthase or isoflavone synthase. Planta 225, 665-679. doi: 10.1007/s00425-006-0368-z

Mahmoud, A. M., Yang, W., and Bosland, M. C. (2014). Soy isoflavones and prostate cancer: a review of molecular mechanisms. J. Steroid. Biochem. Mol. Biol. 140, 116-132. doi: 10.1016/j.jsbmb.2013.12.010

Malla, A., Shanmugaraj, B., Srinivasan, B., Sharma, A., and Ramalingam, S. (2021). Metabolic engineering of isoflavonoid biosynthesis by expressing Glycine max isoflavone synthase in Allium cepa L. for genistein production. Plants 10:52. doi: 10.3390/plants10010052

Mameda, R., Waki, T., Kawai, Y., Takahashi, S., and Nakayama, T. (2018). Involvement of chalcone reductase in the soybean isoflavone metabolon: identification of GmCHR5, which interacts with 2-hydroxyisoflavanone synthase. Plant J. 96, 56-74. doi: 10.1111/tpj.14014

Manning, K. (1998). Isolation of a set of ripening-related genes from strawberry: their identification and possible relationship to fruit quality traits. Planta 205, 622-631. doi: 10.1007/s004250050365

Matsuda, H., Nakayasu, M., Aoki, Y., Yamazaki, S., Nagano, A. J., Yazaki, K., et al. (2020). Diurnal metabolic regulation of isoflavones and soyasaponins in soybean roots. Plant Direct 4:e00286. doi: 10.1002/pld3.286

Matsumura, H., Watanabe, S., Harada, K., Senda, M., Akada, S., Kawasaki, S., et al. (2005). Molecular linkage mapping and phylogeny of the chalcone synthase multigene family in soybean. Theor. Appl. Genet. 110, 1203-1209. doi: 10.1007/ s00122-005-1950-7

Mavandad, M., Edwards, R., Liang, X., Lamb, C. J., and Dixon, R. A. (1990). Effects of trans-cinnamic acid on expression of the bean phenylalanine ammonia-lyase gene family. Plant Physiol. 113, 755-763. doi: 10.1104/pp.94.2.671

McCue, P., and Shetty, K. (2004). Health benefits of soy isoflavonoids and strategies for enhancement: a review. Crit. Rev. Food. Sci. 44, 361-367. doi: 10.1080/ 10408690490509591

Messina, M. J., and Loprinzi, C. L. (2001). Soy for breast cancer survivors: a critical review of the literature. J. Nutr. 131, 3095S-3108S. doi: 10.1093/jn/131. 11.3095S

Messina, M. J., and Wood, C. E. (2008). Soy isoflavones, estrogen therapy, and breast cancer risk; analysis and commentary. Nutr. J. 7:17. doi: 10.1186/14752891-7-17

Misra, P., Pandey, A., Tewari, S. K., Nath, P., and Trivedi, P. K. (2010). Characterization of isoflavone synthase gene from Psoralea corylifolia: a medicinal plant. Plant Cell Rep. 29, 747-755. doi: 10.1007/s00299-0100861-5

Muir, S. R., Collins, G. J., Robinson, S., Hughes, S., Bovy, A., Ric, D. V. C. H., et al. (2001). Overexpression of petunia chalcone isomerase in tomato results in fruit containing increased levels of flavonols. Nat. Biotechnol. 19, 470-474. doi: $10.1038 / 88150$

Mulligan, J. T., and Long, S. R. (1985). Induction of Rhizobium meliloti nodC expression by plant exudate requires nodD. Proc. Nat. Acad.Sci. U.S.A. 82, 6609-6613. doi: 10.1073/pnas.82.19.6609 
Nachvak, S. M., Moradi, S., Anjom-Shoae, J., Rahmani, J., Nasiri, M., Maleki, V., et al. (2019). Soy, soy isoflavones, and protein intake in relation to mortality from all causes, cancers, and cardiovascular diseases: a systematic review and dose-response meta-analysis of prospective cohort studies. J. Acad. Nutr. Diet. 119, 1483-1500. 10.1016/j.jand.2019. 04.011

Nagai, N., Kitauchi, F., Shimosaka, M., and Okazaki, M. (1994). Cloning and sequencing of a full-length cDNA coding for phenylalanine ammonia-lyase from tobacco cell culture. Plant Physiol. 104:1091. doi: 10.1104/pp.104.3. 1091

Napoli, C. A., Fahy, D., Wang, H. Y., and Taylor, L. P. (1999). White anther: a petunia mutant that abolishes pollen flavonol accumulation, induces male sterility, and is complemented by a chalcone synthase transgene. Plant Physiol. 120, 615-622. doi: 10.1104/pp.120.2.615

Nestel, P., Cehun, M., Chronopoulos, A., DaSilva, L., Teede, H., and McGrath, B. (2004). A biochanin-enriched isoflavone from red clover lowers LDL cholesterol in men. Eur. J Clinic. Nutr. 58, 403-408. doi: 10.1038/sj.ejcn.1601796

Nguyen, H. Q., Le, T. H. T., Nguyen, T. N. L., Nguyen, T. G., Sy, D. T., Tu, Q. T., et al. (2020). Overexpressing GmCHI1A increases the isoflavone content of transgenic soybean (Glycine max (L.) Merr.) seeds. In Vitro Cell Dev. Biol. Plant 56, 842-850. doi: 10.1007/s11627-020-10076-x

Ogo, Y., Ozawa, K., Ishimaru, T., Murayama, T., and Takaiwa, F. (2013). Transgenic rice seed synthesizing diverse flavonoids at high levels: a new platform for flavonoid production with associated health benefits. Plant Biotechnol. J. 11, 734-746. doi: 10.1111/pbi.12064

Oldroyd, G. E., Murray, J. D., Poole, P. S., and Downie, J. A. (2011). The rules of engagement in the legume-rhizobial symbiosis. Annu. Rev. Genet. 45, 119-144. doi: 10.1146/annurev-genet-110410-132549

Pandey, A., Misra, P., Khan, M. P., Swarnkar, G., Tewari, M. C., Bhambhani, S., et al. (2014). Co-expression of Arabidopsis transcription factor, AtMYB12, and soybean isoflavone synthase, GmIFS1, genes in tobacco leads to enhanced biosynthesis of isoflavones and flavonols resulting in osteoprotective activity. Plant Biotechnol. J. 12, 69-80. doi: 10.1111/pbi.12118

Paxton, J. D. (1981). Phytoalexins-a working redefinition. J. Phytopathol. 101, 106-109. doi: 10.1111/j.1439-0434.1981.tb03327.x

Perna, S., Peroni, G., Miccono, A., Riva, A., Morazzoni, P., Allegrini, P., et al. (2016). Multidimensional Effects of soy isoflavone by food or supplements in menopause women: a systematic review and bibliometric analysis. Nat. Prod. Commun. 11, 1733-1740. 10.1177/1934578X160110 1127

Philips, D. A., and Tsai, S. M. (1992). Flavonoids as plant signals to rhizosphere microbes. Mycorrhiza 1, 55-58. doi: 10.1007/BF00206136

Price, A. C., Zhang, Y. M., Rock, C. O., and White, S. W. (2001). Structure of $\beta$-ketoacyl-[acyl carrier protein] reductase from Escherichia coli: negative cooperativity and its structural basis. Biochemistry 40, 12772-12781. doi: 10 . 1021/bi010737g

Ralston, L., Subramanian, S., Matsuno, M., and Yu, O. (2005). Partial reconstruction of flavonoid and isoflavonoid biosynthesis in yeast using soybean Type I and Type II chalcone isomerases. Plant Physiol. 137, 1375-1388. doi: $10.1104 /$ pp.104.054502

Rasmussen, S., and Dixon, R. A. (1999). Transgene-mediated and elicitorinduced perturbation of metabolic channeling at the entry point into the phenylpropanoid pathway. Plant Cell. 11, 1537-1551. doi: 10.1105/tpc.11.8. 1537

Reynaud, J., Guilet, D., Terreux, R., Lussignol, M., and Walchshofer, N. (2005). Isoflavonoids in non-leguminous families, an update. Nat. Prod. Rep. 22, $504-$ 515. doi: 10.1039/b416248j

Rípodas, C., Dalla, V., Aguilar, O. M., Zanetti, M. E., and Blanco, F. A. (2013). Knock-down of a member of the isoflavone reductase gene family impairs plant growth and nodulation in Phaseolus vulgaris. Plant Physiol. Biochem. 68, 81-89. doi: 10.1016/j.plaphy.2013.04.003

Ritter, H., and Schulz, G. E. (2004). Structural basis for the entrance into the phenylpropanoid metabolism catalyzed by phenylalanine ammonia-lyase. Plant Cell. 16, 3426-3436. doi: 10.1105/tpc.104.025288

Sarkar, M. A. R., Watanabe, S., Suzuki, A., Hashimoto, F., and Anai, T. (2019). Identification of novel MYB transcription factors involved in the isoflavone biosynthetic pathway by using the combination screening system with agroinfiltration and hairy root transformation. Plant Biotechnol. 36, 241251. doi: 10.5511/plantbiotechnology.19.1025a

Schulze-Lefert, P., Becker-Andre, M., Schulz, W., Hahlbrock, K., and Dangl, J. L. (1989). Functional architecture of the light-responsive chalcone synthase promoter from parsley. Plant Cell. 1, 707-714. doi: 10.1105/tpc.1.7.707

Sepiol, C. J., Yu, J., and Dhaubhadel, S. (2017). Genome-wide identification of chalcone reductase gene family in soybean: insight into root-specific GmCHRs and Phytophthora sojae resistance. Front. Plant Sci. 8:2073. doi: 10.3389/fpls. 2017.02073

Shih, C. H., Chen, Y., Wang, M., Chu, I. K., and Lo, C. (2008). Accumulation of isoflavone genistin in transgenic tomato plants overexpressing a soybean isoflavone synthase gene. J. Agricult. Food Chem. 56, 5655-5661. doi: 10.1021/ jf800423u

Shimada, N., Aoki, T., Sato, S., Nakamura, Y., Tabata, S., and Ayabe, S. (2003). A cluster of genes encodes the two types of chalcone isomerase involved in the biosynthesis of general flavonoids and legume-specific 5-deoxy(iso)flavonoids in Lotus japonicus. Plant Physiol. 131, 941-951. doi: 10.1104/pp.004820

Shimada, N., Nakatsuka, T., Nishihara, M., Yamamura, S., Ayabe, S., and Aoki, T. (2006). Isolation and characterization of a cDNA encoding polyketide reductase in Lotus japonicus. Plant Biotechnol. 23, 509-513. doi: 10.5511/ plantbiotechnology.23.509

Shimamura, M., Akashi, T., Sakura, N., Suzuki, H., Saito, K., Shibata, D., et al. (2007). 2-Hydroxyisoflavanone dehydratase is a critical determinant of isoflavone productivity in hair root cultures of Lotus japonicus. Plant Cell Physiol. 48, 1652-1657. doi: 10.1093/pcp/pcm125

Shin, Y. M., Park, H. J., Yim, S. D., Baek, N. I., Lee, C. H., An, G., et al. (2006). Transgenic rice lines expressing maize $\mathrm{C} 1$ and $\mathrm{R}-\mathrm{S}$ regulatory genes produce various flavonoids in the endosperm. Plant Biotechnol. J. 4, 303-315. doi: 10. 1111/j.1467-7652.2006.00182.x

Sohn, S. I., Kim, Y. H., Kim, S. L., Lee, J. Y., Oh, Y. J., Chung, J. H., et al. (2014). Genistein production in rice seed via transformation with soybean IFS genes. Plant Sci. 217, 27-35. doi: 10.1016/j.plantsci.2013.11.015

Song, Y. E., Wang, X., Shen, Z. W., Xu, Y., and Li, J. Y. (2013). Expressing the maize anthocyanin regulatory gene Lc increased flavonoid content in the seed of white pericarp rice and purple pericarp rice. Russian J. Genet. 49, 1127-1133. doi: 10.7868/s0016675813100123

Spaink, H. P. (1992). Rhizobial lipo-oligosaccharides: answers and questions. Plant Mol. Biol. 20, 977-986. doi: 10.1007/BF00027167

Spaink, H. P., Sheeley, D. M., van Brussel, A. A., Glushka, J., York, W. S., Tak, T., et al. (1991). A novel highly unsaturated fatty acid moiety of lipooligosaccharide signals determines host specificity of Rhizobium. Nature 354, 125-130. doi: 10.1038/354125a0

Sreevidya, V. S., Rao, S. C., Sullia, S. B., Ladha, J. K., and Reddy, P. M. (2006). Metabolic engineering of rice with soybean isoflavone synthase for promoting nodulation gene expression in rhizobia. J. Exp. Bot. 57, 1957-1969. doi: 10.1093/ jxb/erj143

Staunton, J., and Weissman, K. J. (2001). Polyketide biosynthesis: a millennium review. Nat. Prod. Rep. 18, 380-416. doi: 10.1039/a909079g

Steyn, W. J., Holcroft, D. M., Wand, S. J. E., and Jacobs, G. (2004). Anthocyanin degradation in detached pome fruit with reference to preharvest red color loss and pigmentation patterns of blushed and fully red pears. J. Am. Soc. Hort. Sci. 129, 13-19. doi: 10.21273/JASHS.129.1.0013

Subramanian, S., Graham, M. Y., Yu, O., and Graham, T. L. (2005). RNA interference of soybean isoflavone synthase genes leads to silencing in tissues distal to the transformation site and to enhanced susceptibility to Phytophthora sojae. Plant Physiol. 137, 1345-1353. doi: 10.1104/pp.104.05 7257

Subramanian, S., Hu, X., Lu, G., Odell, J. T., and Yu, O. (2004). The promoters of two isoflavone synthase genes respond differentially to nodulation and defense signals in transgenic soybean roots. Plant Mol. Biol. 54, 623-639. doi: 10.1023/B: PLAN.0000040814.28507.35

Subramanian, S., Stacey, G., and Yu, O. (2006). Endogenous isoflavones are essential for the establishment of symbiosis between soybean and Bradyrhizobium japonicum. Plant J. 48, 261-273. doi: 10.1111/j.1365-313X. 2006.02874.x

Sugiyama, A. (2019). The soybean rhizosphere: metabolites, microbes, and beyond-a review. J. Adv. Res. 19, 67-73. doi: 10.1016/j.jare.2019.03.005 
Sun, W., Shen, H., Xu, H., Tang, X., Tang, M., Ju, Z., et al. (2019). Chalcone isomerase a key enzyme for anthocyanin biosynthesis in Ophiorrhiza Japonica. Front. Plant Sci. 10:865. doi: 10.3389/fpls.2019.00865

Taku, K., Melby, M. K., Nishi, N., Omori, T., and Kurzer, M. S. (2011). Soy isoflavones for osteoporosis: an evidence-based approach. Maturitas 70, 333338. doi: 10.1016/j.maturitas.2011.09.001

Teutsch, H. G., Hasenfratz, M. P., Lesot, A., Garnier, J. M., Jeltsch, J. M., Durst, F., et al. (1993). Isolation and sequence of a cDNA encoding the Jerusalem artichoke cinnamate-4-hydroylase, a major plant cytochrome P450 involved in the general phenylpropanoid pathway. Proc. Natl. Acad. Sci. U.S.A. 90, 4102-4107. doi: 10.1073/pnas.90.9.4102

Tian, L., and Dixon, R. A. (2006). Engineering isoflavone metabolism with an artificial bifunctional enzyme. Planta 224, 496-507. doi: 10.1007/s00425-0060233-0

Tikkanen, M. J., and Adlercreutz, H. (2000). Dietary soy-derived isoflavone phytoestrogens: could they have a role in coronary heart disease prevention? Biochem. Pharmacol. 60, 1-5. doi: 10.1016/s0006-2952(99)00409-8

Tsuchihashi, R., Sakamoto, S., Kodera, M., Nohara, T., and Kinjo, J. (2008). Microbial metabolism of soy isoflavones by human intestinal bacterial strains. J. Nat. Med. 62, 456-460. doi: 10.1007/s11418-008-0271-y

Tuteja, J. H., Clough, S. J., Chan, W. C., and Vodkin, L. O. (2004). Tissue-specific gene silencing mediated by a naturally occurring chalcone synthase gene cluster in Glycine max. Plant Cell 16, 819-835. doi: 10.1105/tpc.021352

Vadivel, A. K. A., McDowell, T., Renaud, J. B., and Dhaubhadel, S. (2021). A combinatorial action of GmMYB176 and GmbZIP5 controls isoflavonoid biosynthesis in soybean (Glycine max). Commun. Biol. 4, 1-10. doi: 10.1038/ s42003-021-01889-6

Van, T. A., Koes, R. E., Spelt, C. E., van der Krol, A. R., Stuitje, A. R., and Mol, J. N. (1988). Cloning of the two chalcone flavanone isomerase genes from Petunia hybrida: coordinate, light-regulated and differential expression of flavonoid genes. EMBO J. 7, 1257-1263. doi: 10.1002/j.1460-2075.1988.tb02939.x

Vitale, D. C., Piazza, C., Melilli, B., Drago, F., and Salomone, S. (2013). Isoflavones: estrogenic activity, biological effect and bioavailability. Eur. J. Drug Metab. Pharmacokinet. 38, 15-25. doi: 10.1007/s13318-012-0112-y

Wang, H. C., Huang, X. M., Hu, G. B., and Huang, H. B. (2004). Studies on the relationship between anthocyanin biosynthesis and related enzymes in litchi pericarp. Sci. Agric. Sin. 37, 2028-2032.

Wang, L., Liu, X., Meng, X., Wu, G., and Xu, F. (2018). Cloning and expression analysis of a chalcone isomerase $(\mathrm{CnCHI})$ gene from Chamaemelum nobile. Biotechnology 17, 19-25. doi: 10.3923/biotech.2018.19.25

Wang, Y., Chen, J. Y., Jiang, Y. M., and Lu, W. J. (2007). Cloning and expression analysis of phenylalanine ammonia-lyase in relation to chilling tolerance in harvested banana fruit. Postharvest Biol. Technol. 44, 34-41. doi: 10.1016/j. postharvbio.2006.11.003

Wang, Y. N., Wu, W., Chen, H. C., and Fang, H. (2010). Genistein protects against UVB-induced senescence-like characteristics in human dermal fibroblast by p66Shc down-regulation. J. Dermatol. Sci. 58, 19-27. doi: 10.1016/j.jdermsci. 2010.02.002

Wei, P., Liu, M., Chen, Y., and Chen, D. C. (2012). Systematic review of soy isoflavone supplements on osteoporosis in women. Asian Pac. J. Trop. Med. 5, 243-248. doi: 10.1016/S1995-7645(12) 60033-9

Weisshaar, B., Block, A., Armstrong, G. A., Herrmann, A., Schulze-Lefert, P., and Hahlbrock, K. (1991). Regulatory elements required for light-mediated expression of the Petroselinum crispum chalcone synthase gene. Symp. Soc. Exp. Biol. 45, 191-210.

Welle, R., and Grisebach, H. (1988). Isolation of a novel NADPH-dependent reductase which coacts with chalcone synthase in the biosynthesis of $6^{\prime}$ deoxychalcone. FEBS Lett. 236, 221-225. doi: 10.1016/0014-5793(88)803181

Wu, A. H., Koh, W. P., Wang, R., Lee, H. P., and Yu, M. C. (2008). Soy intake and breast cancer risk in Singapore Chinese Health Study. Br. J. Cancer 99, 196-200. doi: $10.1038 /$ sj.bjc. 6604448
Wu, A. H., Wan, P., Hankin, J., Tseng, C. C., Yu, M. C., and Pike, M. C. (2002). Adolescent and adult soy intake and risk of breast cancer in Asian-Americans. Carcinogenesis 23, 1491-1496. doi: 10.1093/carcin/23.9.1491

Wu, A. H., Ziegler, R. G., Horn-Ross, P. L., Nomura, A. M., West, D. W., Kolonel, L. N., et al. (1996). Tofu and risk of breast cancer in Asian-Americans. Cancer Epidemiol. Prev. Biomarkers. 5, 901-906.

Wu, L. M., Qiao, H. X., Li, Y. K., and Li, L. D. (2007). Cardioprotective effects of the combined use of puerarin and danshensu on acute ischemic myocardial injury in rats. Phytother. Res. 21, 751-756. doi: 10.1002/ptr.2157

Xiang, L., and Moore, B. S. (2005). Biochemical characterization of a prokaryotic phenylalanine ammonia lyase. J. Bacteriol. 187, 4286-4289. doi: 10.1128/JB.187. 12.4286-4289.2005

Yamamoto, S., Sobue, T., Kobayashi, M., Sasaki, S., and Tsugane, S. (2003). Soy, isoflavones, and breast cancer risk in Japan. J. Natl Cancer Inst. 95, 906-913. doi: 10.1093/jnci/95.12.906

Yan, J., Wang, B., Zhong, Y., Yao, L., Cheng, L., and Wu, T. (2015). The soybean R2R3 MYB transcription factor GmMYB100 negatively regulates plant flavonoid biosynthesis. Plant Mol. Biol. 89, 35-48. doi: 10.1007/s11103-0150349-3

Yan, Z., Zhang, X., Li, C., Jiao, S., and Dong, W. (2017). Association between consumption of soy and risk of cardiovascular disease: a meta-analysis of observational studies. Eur. J. Prev. Cardiol. 24, 735-747. doi: 10.1177/ 2047487316686441

Yi, J., Derynck, M. R., Li, X., Telmer, P., Marsolais, F., and Dhaubhadel, S. (2010). A single-repeat MYB transcription factor, GmMYB176, regulates CHS8 gene expression and affects isoflavonoid biosynthesis in soybean. Plant J. 62, 1019-1034.

Yu, O., Jung, W. S., Shi, J., Croes, R. A., Fader, G. M., McGonigle, B., et al. (2000). Production of the isoflavones genistein and daidzein in non-legume dicot and monocot tissues. Plant Physiol. 124, 781-793. 10.1104/pp.124. 2.781

Yu, O., and McGonigle, B. (2005). Metabolic engineering of isoflavone biosynthesis. Adv. Agron. 86, 147-190. doi: 10.1016/S0065-2113(05)86003-1

Yu, O., Shi, J., Hession, A. O., Maxwell, C. A., McGonigle, B., and Odell, C. A. (2003). Metabolic engineering to increase isoflavone biosynthesis in soybean seed. Phytochemistry 63, 753-763. doi: 10.1016/s0031-9422(03) 00345-5

Zhang, P., Du, H., Wang, J., Pu, Y., Yang, C., Yan, R., et al. (2020). Multiplex CRISPR/Cas9-mediated metabolic engineering increases soya bean isoflavone content and resistance to soya bean mosaic virus. Plant Biotechnol. J. 18, 1384-1395. doi: 10.1111/pbi.13302

Zhao, M., Wang, T., Wu, P., Guo, W., Su, L., Wang, Y., et al. (2017). Isolation and characterization of GmMYBJ3, an R2R3-MYB transcription factor that affects isoflavonoids biosynthesis in soybean. PLoS One. 12:e0179990. doi: 10.1371/ journal.pone.0179990

Zhou, Y., Huang, J. L., Zhang, X. L., Zhu, L. M., Wang, X. F., Guo, N., et al. (2018). Overexpression of chalcone isomerase (CHI) increases resistance against Phytophthora sojae in soybean. J. Plant Biol. 61, 309-319. doi: 10.1007/ s12374-018-0017-7

Conflict of Interest: YJO was employed by the company Institute for Future Environmental Ecology Co., Ltd., Jeonju, South Korea.

The remaining authors declare that the research was conducted in the absence of any commercial or financial relationships that could be construed as a potential conflict of interest.

Copyright (c) 2021 Sohn, Pandian, Oh, Kang, Cho and Cho. This is an open-access article distributed under the terms of the Creative Commons Attribution License (CC BY). The use, distribution or reproduction in other forums is permitted, provided the original author(s) and the copyright owner(s) are credited and that the original publication in this journal is cited, in accordance with accepted academic practice. No use, distribution or reproduction is permitted which does not comply with these terms. 